\title{
An A-train and MERRA view of cloud, thermodynamic, and dynamic variability within the subtropical marine boundary layer
}

\author{
Brian H. Kahn ${ }^{1}$, Georgios Matheou ${ }^{1}$, Qing Yue ${ }^{1}$, Thomas Fauchez ${ }^{2}$, Eric J. Fetzer ${ }^{1}$, Matthew Lebsock ${ }^{1}$, \\ João Martins ${ }^{3}$, Mathias M. Schreier ${ }^{1}$, Kentaroh Suzuki ${ }^{4}$, and João Teixeira ${ }^{1}$ \\ ${ }^{1}$ Jet Propulsion Laboratory, California Institute of Technology, Pasadena, CA, USA \\ ${ }^{2}$ NASA Goddard Space Flight Center, Greenbelt, MD, USA \\ ${ }^{3}$ Department of Meteorology and Geophysics, Instituto Português do Mar e da Atmosfera, Lisbon, Portugal \\ ${ }^{4}$ Division of Climate System Research, Atmosphere and Ocean Research Institute, The University of Tokyo, Kashiwa, Japan \\ Correspondence to: Brian H. Kahn (brian.h.kahn@jpl.nasa.gov)
}

Received: 23 January 2017 - Discussion started: 6 February 2017

Revised: 4 July 2017 - Accepted: 6 July 2017 - Published: 7 August 2017

\begin{abstract}
The global-scale patterns and covariances of subtropical marine boundary layer (MBL) cloud fraction and spatial variability with atmospheric thermodynamic and dynamic fields remain poorly understood. We describe an approach that leverages coincident NASA A-train and the Modern Era Retrospective-Analysis for Research and Applications (MERRA) data to quantify the relationships in the subtropical MBL derived at the native pixel and grid resolution. A new method for observing four subtropical oceanic regions that capture transitions from stratocumulus to trade cumulus is demonstrated, where stratocumulus and cumulus regimes are determined from infrared-based thermodynamic phase. Visible radiances are normally distributed within stratocumulus and are increasingly skewed away from the coast, where trade cumulus dominates. Increases in MBL depth, wind speed, and effective radius $\left(r_{\mathrm{e}}\right)$, and reductions in 700$1000 \mathrm{hPa}$ moist static energy differences and 700 and $850 \mathrm{hPa}$ vertical velocity correspond with increases in visible radiance skewness. We posit that a more robust representation of the cloudy MBL is obtained using visible radiance rather than retrievals of optical thickness that are limited to a smaller subset of cumulus. The method using the combined A-train and MERRA data set has demonstrated that an increase in $r_{\mathrm{e}}$ within shallow cumulus is strongly related to higher MBL wind speeds that further correspond to increased precipitation occurrence according to CloudSat, previously demonstrated with surface observations. Hence, the combined data sets have the potential of adding global context to process-level understanding of the MBL.
\end{abstract}

\section{Introduction}

Much of the uncertainty in projections of future climate is directly or indirectly related to clouds and their associated processes (IPCC, 2013), including shallow marine cumuliform clouds (Bony and Dufrense, 2005). The low-cloud-climate feedback is generally regarded to be positive (e.g., Clement et al., 2009). Many studies, however, suggest that the sign and magnitude of the feedback are cloud-type-dependent (e.g., Caldwell et al. 2013; Bretherton et al., 2013; Dal Gesso et al., 2015; Stephens, 2005; Yue et al., 2017; Zelinka et al., 2012).

Using large eddy simulation (LES) experiments forced with doubled $\mathrm{CO}_{2}$, Bretherton et al. (2013) show that the gradient of relative humidity $(\mathrm{RH})$ from the marine boundary layer (MBL) to the free troposphere is a key factor that controls the shortwave cloud radiative feedback. Rieck et al. (2012) used LES forced by perturbed lower-tropospheric temperature profiles with fixed RH to show that an increase in surface moisture fluxes leads to a drying of the tradecumulus-topped MBL. The drying overwhelms the increased shortwave reflection from the liquid water lapse rate feedback, thus leading to reduced cloudiness and a positive shortwave cloud feedback. These mechanisms are also discussed by Nuijens and Stevens (2012) in the context of bulk theory and clearly demonstrate that free-tropospheric temperature and moisture gradients act as constraints for climate-changeinduced surface flux changes. 
While the constant RH framework is a useful concept to investigate cloud-climate feedback in simplified modeling experiments, an overall reduction of RH in the subtropical free troposphere was found in the Coupled Model Intercomparison Project Phase 3 (CMIP3; Sherwood et al., 2010; Fasullo and Trenberth, 2012) and Phase 5 (CMIP5; Lau and Kim, 2015) archives with a non-negligible spread in the changing magnitude and vertical structure of RH among the models. Therefore, the assumption that constant RH might hold across the diversity of subtropical cloud regimes with a changing climate is likely not valid. Medeiros and Nuijens (2016) showed that the RH gradient between the MBL and lower free troposphere is widely variable among the CMIP5 models within the trade cumulus regime. Therefore, further examination of cloud variability and the vertical structure of RH with present-day satellite and reanalysis observations is warranted.

A strong linkage between cloud amount and estimated inversion strength (EIS; Wood and Bretherton, 2004), lowertropospheric stability (LTS) (Klein and Hartmann, 1993), and moist static energy differences (dMSE) between the free troposphere and surface (Kawai and Teixeira, 2010; Chung et al., 2012; Kubar et al., 2015) is well understood. Satellite observations of the MBL have revealed prodigious variations of cloud organization that span orders of magnitude over spatial and temporal scales (Cahalan et al., 1994; Wood and Hartmann, 2006; Muhlbauer et al., 2014). Even for a fixed value of cloud fraction, a large diversity of statistical variability may be observed (Kawai and Teixeira, 2012). Correlations of cloud fraction to other environmental variables are highly dependent on the timescale of comparison (e.g., Brueck et al., 2015). At present, the relationships of cloud fraction and spatial variability to larger-scale properties other than EIS/LTS remain poorly understood. Furthermore, previous work has emphasized correlations of MBL cloud properties to $500 \mathrm{hPa}$ vertical velocity and RH that are averaged over monthly, seasonal, or annual timescales. Kawai and Teixeira (2010) found significant correlations for instantaneous observations of cloud inhomogeneity and the skewness of liquid water path (LWP) to thermodynamic structure changes between 850 and $1000 \mathrm{hPa}$; the correlations are larger for LWP than with cloud fraction.

Modeling and observational studies have demonstrated that the vertical structures of moments of conserved thermodynamic variables depend on the cloud regime (e.g., Suselj et al., 2013; Ghate et al., 2016; Zhu and Zuidema, 2009). Substantial differences exist between stratocumulus and trade cumulus in the mean, variance, skewness, and kurtosis of equivalent potential temperature $\theta_{\mathrm{e}}$, liquid water potential temperature $\theta_{1}$, and vertical velocity profiles, and they point to the importance of a global perspective uniquely provided by satellite and reanalysis data. The NASA A-train (Stephens et al., 2002) provides a wealth of remote-sensing data about the microphysics and thermodynamics of the cloudy MBL. Reanalysis data such as the Modern Era Retrospective-Analysis for Research and Applications (MERRA; Rienecker et al., 2011) offer a complementary set of thermodynamic and dynamic variables that help establish a larger-scale perspective for coincident remote-sensing observations.

Our primary purpose is to investigate instantaneous relationships between cloud microphysical and optical properties, dynamics, and thermodynamic variables from the Atrain and MERRA at the native temporal and spatial resolution of the observations. The satellite and reanalysis data each provide unique information that should ideally be combined together at the native resolution rather than relying on one instrument or reanalysis alone, or combining over time and space averages. The geophysical fields are retained at the native spatial and temporal resolution such that the instantaneous spatial "snapshots" of the cloud probability density function (PDF) are preserved and are then conditioned by available thermodynamic and dynamic variables. This approach removes the temporal variability in order to focus on the spatial variability and covariances. The statistical behavior of cloud properties, and how the thermodynamic and dynamic state variables are related to them, is thus inferred using the finest temporal and spatial resolutions available. The different instruments and reanalysis data sets are treated as "building blocks" that construct a simultaneous view of the MBL, playing on the strengths of each data set. This holistic synthesis of multivariate and multimoment data sets may highlight aspects of MBL structure that are otherwise overlooked. The MBL structures of interest are summarized in Nuijens et al. (2009) using surface-based observations and demonstrate testable relationships between clouds, wind, humidity, and precipitation. Lastly, the approach taken herein may ultimately enhance our ability to quantify the complex time, space, and cloud regime coupling of clouds and circulation (Bony et al., 2015).

Section 2 describes the data sets used, while Sect. 3 details the methodological approach taken in this investigation. Section 4 details the regional maps, while Sect. 5 examines the joint PDFs. We conclude in Sect. 6.

\section{Data}

The Atmospheric Infrared Sounder (AIRS)/Advanced Microwave Sounding Unit (AMSU) sounding suite located on board NASA's Earth Observing System (EOS) Aqua satellite has obtained vertical profiles of temperature and water vapor at approximately $45 \mathrm{~km}$ horizontal resolution since September 2002 (Chahine et al., 2006). While AIRS cannot capture the sharpness of the temperature and water vapor mixing ratio gradients across the top of the MBL (Maddy and Barnet, 2008; Yue et al., 2011), the coarse-resolution vertical gradients from the surface to the lower free troposphere are obtained with high fidelity as shown in validation studies using numerical weather prediction model data or radiosondes (Yue et al., 2013; Kalmus et al., 2015). The AIRS 
operational products also provide numerous cloud variables that include effective cloud fraction (ECF), cloud thermodynamic phase (liquid, ice, and unknown categories), and others (Kahn et al., 2014). A MBL depth estimate inferred from the height/pressure of maximum RH gradient is described and validated with radiosondes launched during the Rain in Shallow Cumulus over the Ocean (RICO) campaign in Martins et al. (2010).

The AIRS version 5 channel 4 visible spectral radiance (0.49-0.94 $\mu \mathrm{m})$ (Gautier et al., 2003; Aumann et al., 2006) with a nadir spatial resolution of $2.28 \mathrm{~km}$ is used and has units of $\mathrm{W} \mathrm{m}^{-2} \mu \mathrm{m}^{-1} \mathrm{sr}^{-1}$. AIRS visible-band data are coregistered to the AIRS IR footprint such that 72 visible pixels are aligned within every footprint. A prototype AIRS visible cloud mask (Gautier et al., 2003) that was developed to support earlier algorithm development efforts is also used. Although the cloud mask has not been compared directly against benchmarks such as the Moderate-Resolution Imaging Spectroradiometer (MODIS) cloud mask, manual inspection suggests that this cloud mask tends towards clear-sky conservative and captures many shallow, broken subpixel cumulus clouds.

The MODIS instrument on EOS Aqua is capable of observing a wide variety of land, ocean, and atmospheric variables (Platnick et al., 2017) that are collocated to the AIRS field of view (FOV). We use the Collection 6 liquid phase cloud optical thickness $\tau$ and effective radius $r_{\mathrm{e}}$ retrievals from the MYD06_L2 swath product and the $1 \mathrm{~km}$ cloud mask from the MYD035_L2 swath product. Platnick et al. (2017) show that the $r_{\mathrm{e}}$ change between C5.1 and C6 is $\pm 1-2 \mu \mathrm{m}$. We have tested the differences in the PDFs between C5.1 and C6 for a subset of the data investigated, and very little change in the PDFs was observed (not shown). The MODIS liquid cloud $r_{\mathrm{e}}$ is used as a proxy for precipitation and is verified with the CloudSat 2C-RAIN-PROFILE (Release 4) precipitation product (L'Ecuyer and Stephens, 2002).

The MERRA instantaneous, 6-hourly, native-resolution, gridded data sets at $1 / 2^{\circ} \times 2 / 3^{\circ}$ (Rienecker et al., 2011) are used to assess the thermodynamic profiles derived from AIRS, assign vertical profiles of horizontal $u$ and $v$ wind components, and assign vertical profiles of pressure velocity $\omega$ in the MBL and lower free troposphere. All of the instantaneous MERRA data are spatially and temporally matched to the A-train orbit using a nearest-neighbor matching approach with no time interpolation.

The matching approach uses a nearest-neighbor technique weighted by the sensor spatial response function (Schreier et al., 2010). The mean, variance, and skewness of MODIS cloud properties at 1 or $5 \mathrm{~km}$ resolution is retained within a larger $45 \mathrm{~km}$ resolution AIRS/AMSU field of regard (FOR), while MERRA's $1 / 2^{\circ} \times 2 / 3^{\circ}$ resolution thermodynamic and dynamic variables are matched to the nearest AIRS/AMSU FOR.

\section{Methodology}

Four subtropical oceanic regions that capture transitions from stratocumulus to trade cumulus are investigated. The four regions are greatly expanded in scale from those used in Klein and Hartmann (1993) to investigate the stratocumulustopped MBL and are listed in Table 1. While all available daytime (ascending) orbits from 1 January 2009 to 31 December 2009 were used, the remaining discussion is limited to the seasons that contain the observed peak in cloud frequency listed in Table 1 (Klein and Hartmann, 1993).

Figure 1a is an example visible image for a 6 min AIRS granule within the southeast Atlantic Ocean (SEA). The visible band captures various spatial structures of clouds. The cloud mask derived from AIRS visible bands for the same granule is shown in Fig. 1b. The cloud mask is used to narrow down the spatial sampling for the following analysis. The cloud mask likely includes instances of clear sky, but the approach only requires a coarse masking approach to filter out a majority of the clear-sky pixels. We will discuss implications regarding the filtering process in Sect. 4.

Removal of pixels containing mid- and high-level clouds helps to reduce ambiguities introduced by free-tropospheric clouds and also a portion of the thermodynamic and dynamic variability associated with cloudy areas of synoptic-scale waves. Figure 2 shows the AIRS infrared $T_{\mathrm{b}}$ within a clean atmospheric window at $1231 \mathrm{~cm}^{-1}$, the cloud thermodynamic phase mask, three constant pressure levels of AIRS RH (700, 850 , and $925 \mathrm{hPa}$ ), and the skewness of visible radiance for the same granule shown in Fig. 1. The cloud thermodynamic phase identifies some scattered ice in the northern portion of the granule. All pixels identified with ice are removed in the following analysis. Jin and Nasiri (2014) showed that AIRS successfully identifies the presence of ice within the AIRS FOV in excess of $90 \%$ of the time when compared to Cloud-Aerosol Lidar and Infrared Pathfinder Satellite Observations (CALIPSO) thermodynamic phase estimates at the pixel scale. A similar approach is taken in Nam et al. (2012) and Myers and Norris (2015) to minimize impacts from convection and synoptic-scale weather systems. Additional occurrences of $T_{\mathrm{b}, 1231}<273 \mathrm{~K}$ that potentially contain supercooled liquid phase mid-level clouds are also removed.

As the AIRS cloud phase algorithm is based on a channel selection that exploits differences in the index of refraction for liquid and ice, the cloud amount observed in the AIRS pixel is frequently small enough that the spectral signature does not trigger a positive liquid test (e.g., Jin and Nasiri, 2014). The ECF for these unknown phase cases can simultaneously be well above the sensitivity of cloud detection (validated using CALIPSO lidar; see Kahn et al., 2014). As a result, none of the phase tests are triggered even though cloud is observed within the AIRS pixel. These unknown cases line up very well with the frequency of trade cumulus in the four regions selected based on inspection of individ- 


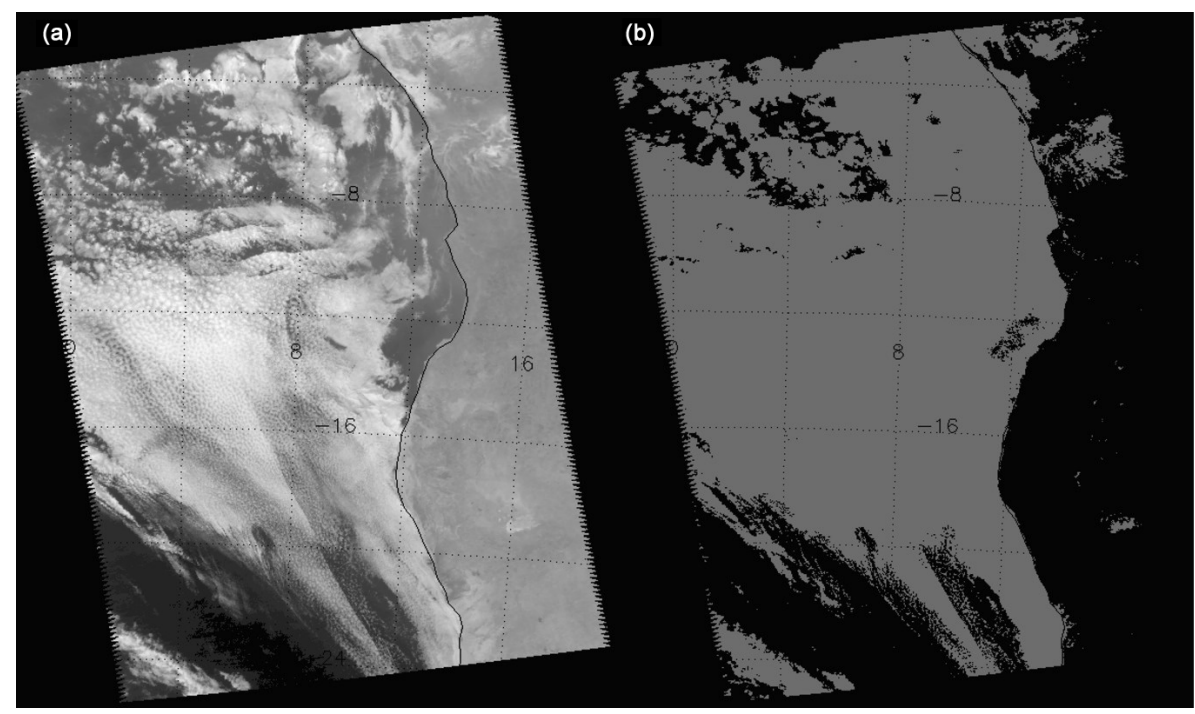

Figure 1. AIRS version 5 visible channel 4 radiance $(0.49-0.94 \mu \mathrm{m})$ at a nadir spatial resolution of $2.28 \mathrm{~km}$ (left), and AIRS cloud mask (binary clear and cloudy) determined from visible channel thresholds (right). See Gautier et al. (2003) for more details.

Table 1. The four regions investigated in this study are greatly expanded in area from Klein and Hartmann (1993). The four columns with percentages and total counts are defined at the AIRS/AMSU field-of-regard (FOR) spatial scale. The three cloudy categories indicate whether clouds of that type occur with any frequency within the AIRS/AMSU FOR. Clear sky is defined over the entire AIRS/AMSU FOR and is therefore very infrequent.

\begin{tabular}{|c|c|c|c|c|c|c|c|c|}
\hline Region & Abbrev & Season & Location & $\% \mathrm{Sc}$ & $\% \mathrm{Cu}$ & $\%$ Other & $\% \mathrm{Clr}$ & Counts \\
\hline $\begin{array}{l}\text { Northeast } \\
\text { Pacific } \\
\text { Ocean }\end{array}$ & NEP & JJA & $\begin{array}{l}15-35^{\circ} \mathrm{N} \\
110-150^{\circ} \mathrm{W}\end{array}$ & 23.3 & 64.8 & 10.7 & 1.3 & 186133 \\
\hline $\begin{array}{l}\text { Northeast } \\
\text { Atlantic } \\
\text { Ocean }\end{array}$ & NEA & JJA & $\begin{array}{l}15-35^{\circ} \mathrm{N} \\
10-50^{\circ} \mathrm{W}\end{array}$ & 8.1 & 72.0 & 18.0 & 1.9 & 183798 \\
\hline $\begin{array}{l}\text { Southeast } \\
\text { Pacific } \\
\text { Ocean }\end{array}$ & SEP & SON & $\begin{array}{l}5-25^{\circ} \mathrm{S} \\
70-110^{\circ} \mathrm{W}\end{array}$ & 25.5 & 69.6 & 3.9 & 1.0 & 184208 \\
\hline $\begin{array}{l}\text { Southeast } \\
\text { Atlantic } \\
\text { Ocean }\end{array}$ & SEA & SON & $\begin{array}{l}5-25^{\circ} \mathrm{S} \\
25^{\circ} \mathrm{W}-15^{\circ} \mathrm{E}\end{array}$ & 31.8 & 62.1 & 4.4 & 1.7 & 180668 \\
\hline
\end{tabular}

ual granule data (e.g., Figs. 1 and 2) and gridded seasonal averages (Sect. 4).

The AIRS liquid detections coincide with uniform stratocumulus (Fig. 1) with close to normally distributed visible radiances (lower right, Fig. 2), while unknown detections correspond well to shallow cumulus with a distinctive positively skewed visible radiance, very similar to previous results obtained using LWP (Wood and Hartmann, 2006; Kawai and Teixeira, 2010). Previous investigations have used free-tropospheric vertical velocity to separate cloud regime types (e.g., Bony and Dufresne, 2005; Medeiros and Stevens, 2011; Nam et al., 2012). Henceforth, the two regimes defined exclusively by liquid and unknown phase detections will be generically referred to as stratocumulus and cumulus regimes, respectively. An advantage of this instantaneous approach is that the temporal and spatial variations of cumulus and stratocumulus cloud areas are more precisely separated from each other.

For the AIRS/AMSU FORs containing MBL clouds, the coincident AIRS and MODIS geophysical fields are collocated. The AIRS ECF is averaged over the entire AIRS/AMSU FOR where clear sky is equal to a value of 0 . The AIRS thermodynamic phase is averaged over cloudy AIRS FOVs only. The individual phase tests are summed and liquid is defined for values $<-0.8$, unknown between -0.8 and +0.8 , and ice for values $>+0.8$. The MODIS cloud mask and $\tau$ are averaged over the entire AIRS/AMSU FOR. The MODIS $r_{\mathrm{e}}$ is averaged only over the successful retrievals that 
(a)

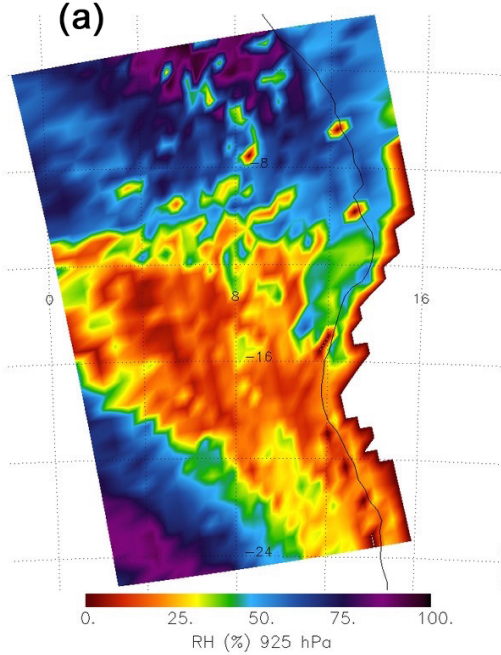

(d)

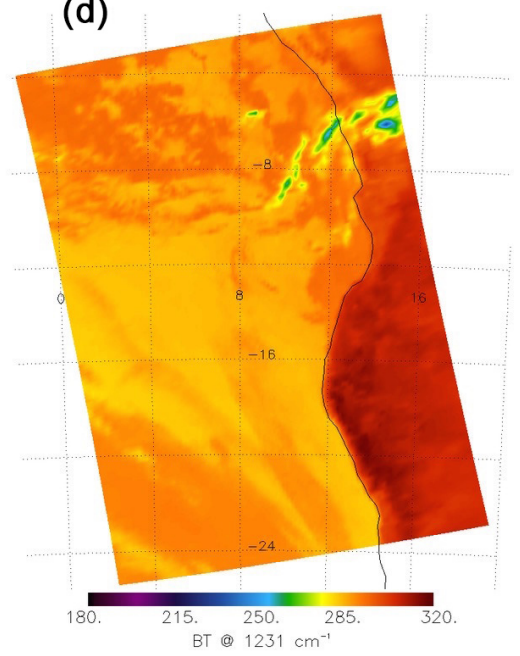

(b)

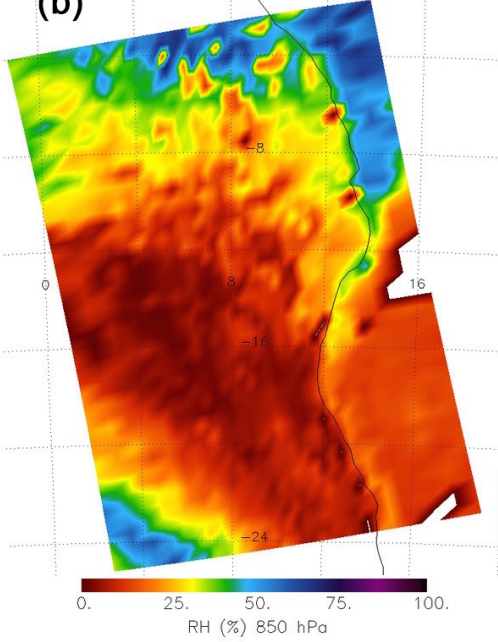

(e)

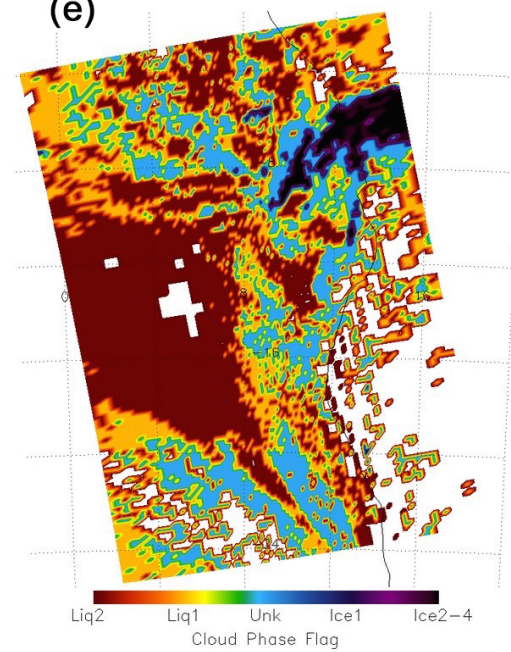

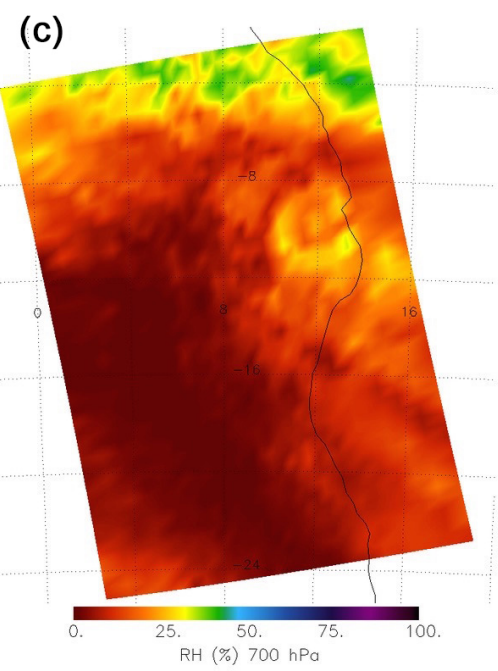

(f)

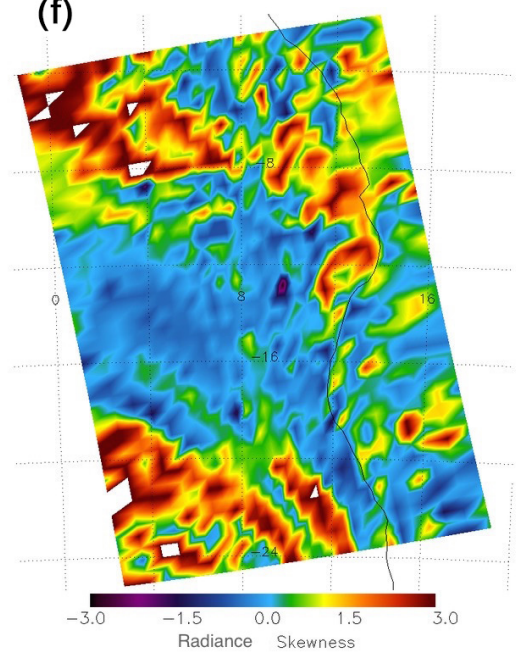

Figure 2. AIRS (a) $\mathrm{RH}_{925}(\%)$, (b) $\mathrm{RH}_{850}(\%)$, (c) $\mathrm{RH}_{700}(\%)$, (d) $1231 \mathrm{~cm}^{-1} T_{\mathrm{b}}(\mathrm{K})$, (e) cloud thermodynamic phase, and (f) radiance skewness from visible channel 4. The granule is identical to the one shown in Fig. 1.

are a subset of MODIS pixels identified as containing cloud. The nearest neighbor is matched for MERRA geophysical fields at a similarly sized spatial resolution. The mean, standard deviation, and skewness of MODIS and AIRS FOV properties are then calculated for each AIRS/AMSU FOR separately. Therefore, multiple satellite instrument and reanalysis observations at multiple spatial scales can be linked together through joint PDFs for a large combination of statistical moments. These data serve as the basis of the following investigation.

\section{Regional spatial averages}

Regional-scale, seasonal averages are calculated from the pixel-scale data described in Sect. 3 for 90 daytime (130 pm Equator-crossing time) snapshots and are then re-gridded to $1^{\circ} \times 1^{\circ}$ spatial resolution and help facilitate comparisons to previous studies. Figure 3 shows the visible radiance skewness for JJA in the northeast Pacific (NEP) and northeast Atlantic (NEA) regions, and SON in the southeast Pacific (SEP) and SEA regions, with an overlay of AIRS total ECF. The coastal stratocumulus radiances are distributed approximately normally, while the radiances are positively skewed away from the coast, where disorganized cumulus dominates (e.g., Wood and Hartmann, 2006). Contours of the magnitude of radiance skewness closely align with the magnitude of ECF in cumulus but much less so in proximity to the coast within stratocumulus. Very poor spatial correspondence between radiance skewness and the mean value of MODIS cloud fraction was found (not shown) and is consistent with low correlations between Geostationary Operational Environmental Satellite (GOES)-derived cloud fraction and LWP noted by Kawai and Teixeira (2010) in the SEP region. Interestingly, the average radiance skewness is larger and ECF 
is smaller in the NEA than the other three regions, which is consistent with other satellite observations (Klein and Hartmann, 1993; Rossow and Schiffer, 1999) and ship-based observations (Wood, 2012). The patterns of radiance skewness shown in Fig. 3 also resemble typical climatological patterns of cloud sizes reported in Wood and Field (2011) and cloud texture as viewed from the Multi-angle Imaging SpectroRadiometer (MISR) (Zhao et al., 2016).

Values of MODIS total water path (TWP) skewness do not show a clear transition from normally distributed to positively skewed values in Weber et al. (2011). This further motivates the removal of mid- and high-level cloud occurrences using the AIRS phase mask that comprise anywhere from 4 to $18 \%$ of the total number of FOVs depending on the region of study (Table 1). The total number of collocated data points within each region is roughly $\sim 180,000$. However, the AIRS and MODIS cloud fields have smaller spatial resolutions that are aggregated to the AIRS/AMSU field of regard, and the raw counts for these fields number in the millions. Oreopoulos and Cahalan (2005) show that the inhomogeneity parameter calculated from MODIS LWP, rather than TWP, is most homogeneous near the coast and indicates increasing heterogeneity that extends into the cumulus regimes. We argue that the results of Oreopoulos and Cahalan (2005) are more definitive than those shown in Weber et al. (2011) and more closely resemble the gradients and magnitudes contained within Fig. 3.

There are several factors that contribute to relationships between ECF and the various moments of radiance. A reduced ECF and increased radiance skewness (Fig. 3) may indicate smaller cloud sizes, but this is probably not universally true. If the cloud optical thickness is decreased, the ECF is also decreased from reductions in cloud emissivity even though cloud coverage itself may remain constant. (Recall that the ECF is a convolution of emissivity and cloud fraction.) If the cloud optical thickness is fixed, the cloud emissivity remains fixed even though the cloud coverage itself and ECF could be decreased. The ECF could also be decreased (increased) if small cloud elements become more widely spaced (packed together), assuming the cloud sizes of the individual cumulus elements remain the same. With respect to the visible radiances, the radiance is decreased if cloud elements become smaller than the nominal $2.2 \mathrm{~km}$ pixel size, assuming the optical thickness of the cloud elements does not change. Therefore, if an increased proportion of a cloud population with normally distributed radiances becomes subpixel in size, one would expect a shift towards positive skewness. If cloud distributions are spatially resolved, an increased skewness radiance is still entirely possible if the optical thickness of cloud distributions is skewed itself. However, in this investigation, the skewness of the MODIS optical thickness is less skewed at low ECF than visible radiance (not shown). This suggests that the skewness in the visible radiance at low ECF at least partially arises from smaller cloud sizes.
The mean MBL depth (Fig. 4) reaffirms a characteristic transition from shallow MBLs (920-970 hPa) near the coast to deeper MBLs (830-880 hPa) to the west and is a wellobserved feature of the stratocumulus-to-cumulus transition previously observed by Karlsson et al. (2010), Teixeira et al. (2011), and others. Closest to the coast, the MBL is shallowest in the NEA and slightly deeper in the NEP. The SEA and SEP are deeper than their Northern Hemisphere (NH) counterparts, with SEP the deepest. The SEP MBL depths agree with VAMOS Ocean-Cloud-Atmosphere-Land Study Regional Experiment (VOCALS-REx) in situ radiosondederived temperature inversion base heights described by Bretherton et al. (2010). Furthermore, the inter-regional differences in MBL depth show consistency with Global Positioning System-radio occultation (GPS-RO) data described by Chan and Wood (2013).

dMSE between 700 and $1000 \mathrm{hPa}$ are calculated following the approach outlined by Kubar et al. (2012) and are also shown in Fig. 4. The dMSE is calculated from quality-controlled AIRS soundings (PGood $\geq 1000 \mathrm{hPa}$ ) and is nearly identical to estimates from ERA-Interim shown by Kubar et al. (2012). The magnitude of dMSE is larger and positive near the coast in the Southern Hemisphere (SH) compared to the $\mathrm{NH}$ and is somewhat reduced in the NEA region. Yue et al. (2011) showed that values of EIS and LTS obtained from AIRS soundings are lower in the NEA compared to the other three regions and are also consistent with Fig. 4.

Seasonal averages of AIRS $\mathrm{RH}_{700}$ with an overlay of the corresponding MERRA-AIRS $\mathrm{RH}_{700}$ differences are shown in Fig. 5. Wind vectors depict the mean horizontal flow. Overall, $\mathrm{RH}_{700}$ in the $\mathrm{SH}$ is lower than the $\mathrm{NH}$, while the NEA is the moistest of the four regions, and SEP the driest. MERRA is on average moister than AIRS by $\sim 5 \%$ in the $\mathrm{NH}$, nearly identical to AIRS in the SEA, and a much more spatially heterogeneous difference is observed in the SEP from the coastal proximity westward between 8 and $12^{\circ} \mathrm{S}$.

Bretherton et al. (2010) demonstrate that the free troposphere in the SEP westward of $75^{\circ} \mathrm{W}$ is characteristically very dry $\left(0.1 \mathrm{~g} \mathrm{~kg}^{-1}\right)$ with sporadic filaments of moist air (as high as $3-6 \mathrm{~g} \mathrm{~kg}^{-1}$ ) up to an altitude of $2.5 \mathrm{~km}$. In addition, these moist filaments have been observed with GPS-RO refractivity profiles by von Engeln et al. (2007). The vertical structure of RH obtained from VOCALS-REx radiosondes implies a well-mixed MBL near the coast with MBL decoupling west of $80^{\circ} \mathrm{W}$. Myers and Norris (2015) showed that $700 \mathrm{hPa}$ is drier in the $\mathrm{SH}$ subtropics than in the NH using ERA-Interim data. When general circulation models are sampled for RICO-like conditions using representative midtropospheric large-scale vertical velocities as in Medeiros and Stevens (2011), a dry bias is obtained above the MBL in comparison to a composite of RICO radiosondes.

The seasonal averages of AIRS $\mathrm{RH}_{850}$, and the corresponding MERRA-AIRS $\mathrm{RH}_{850}$ differences, are larger than those found for $\mathrm{RH}_{700}$ (Fig. 6) and are due to temperature 

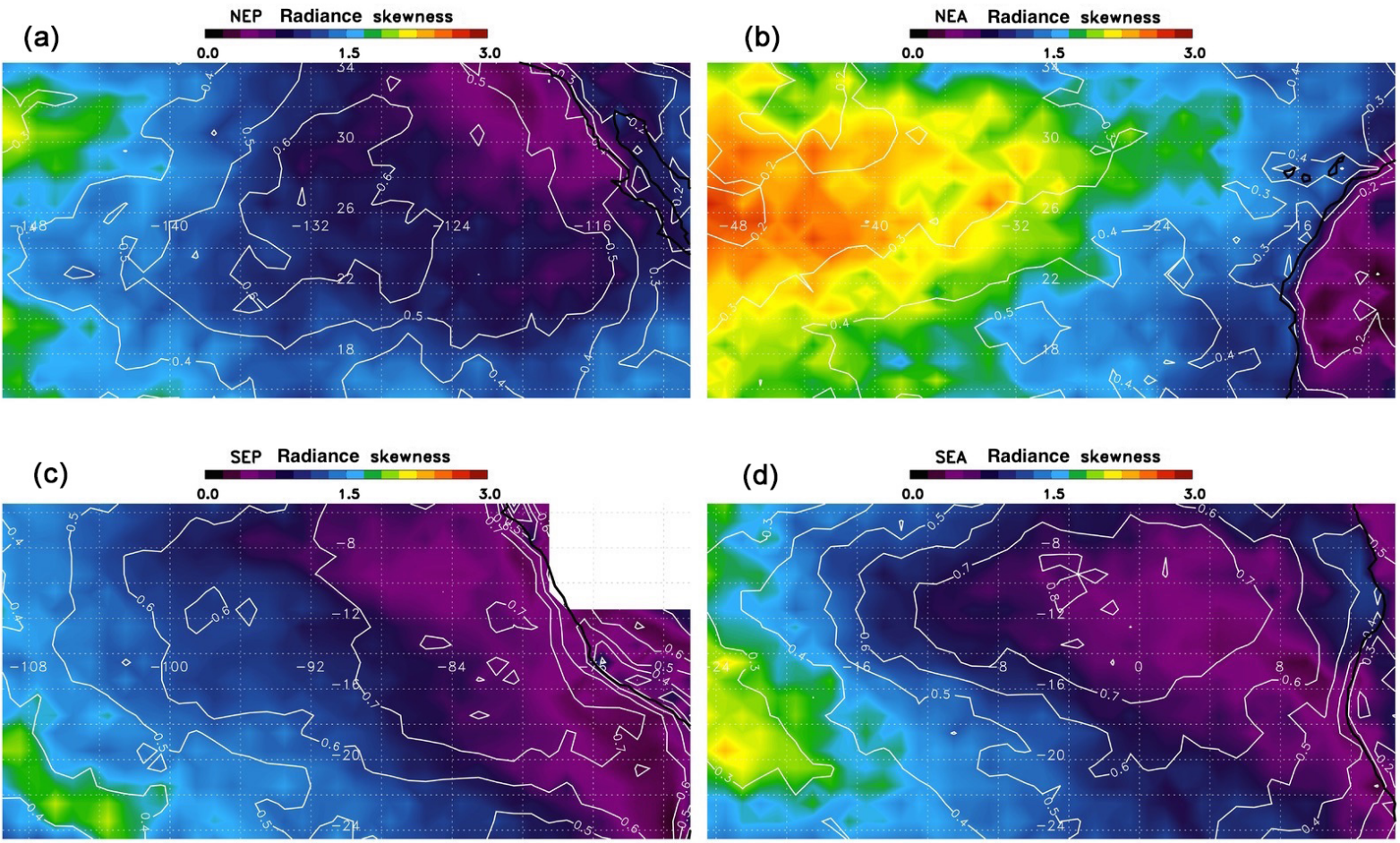

Figure 3. Radiance skewness for regions listed in Table 1: (a) NEP, (b) NEA, (c), SEP, and (d) SEA. The AIRS ECF is overlaid as white contours.
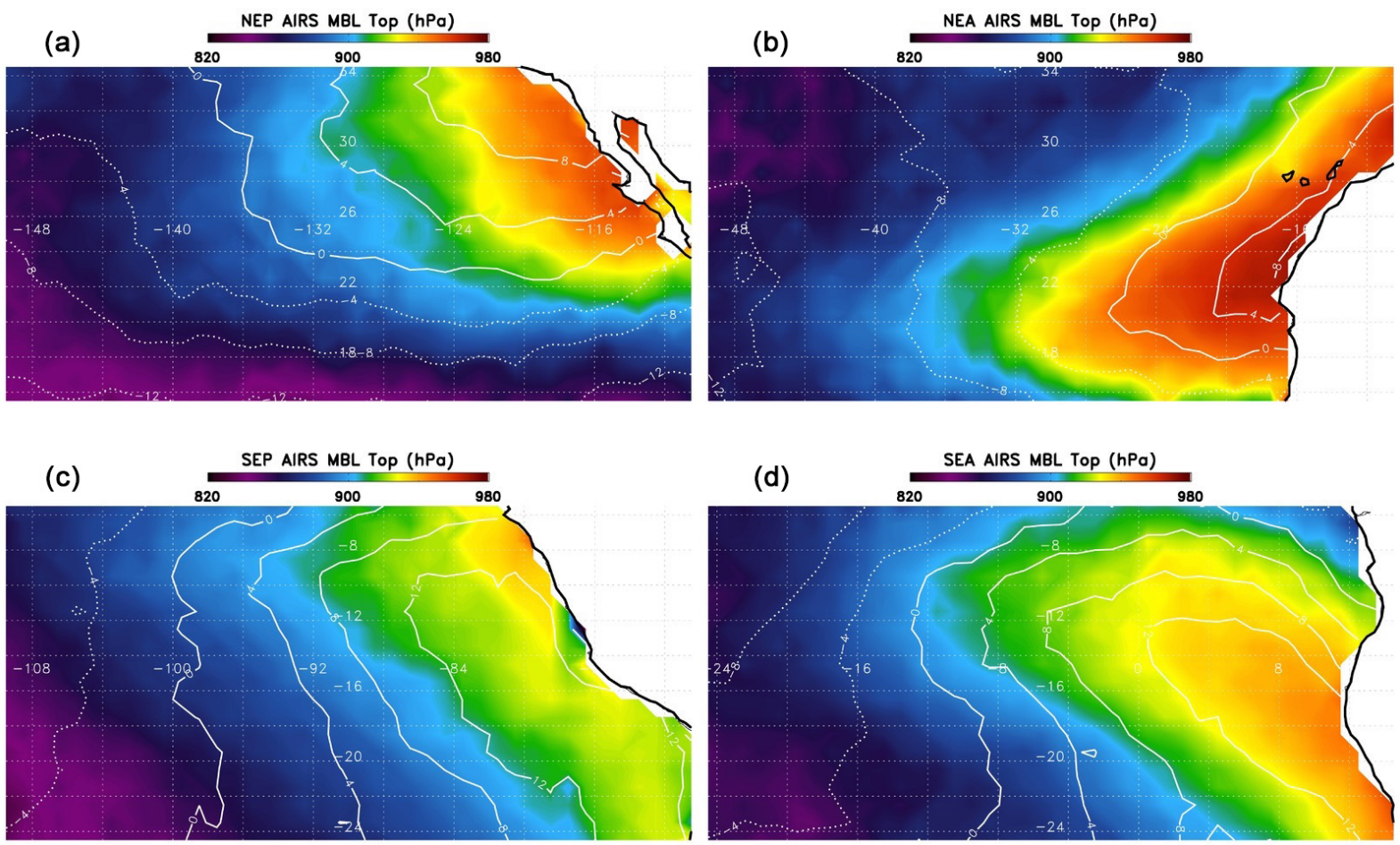

Figure 4. MBL depth (hPa) for regions listed in Table 1: (a) NEP, (a) NEA, (c), SEP, and (d) SEA. The AIRS 1000-700hPa dMSE is overlaid in white contours (solid are for positive, and dashed for negative). 

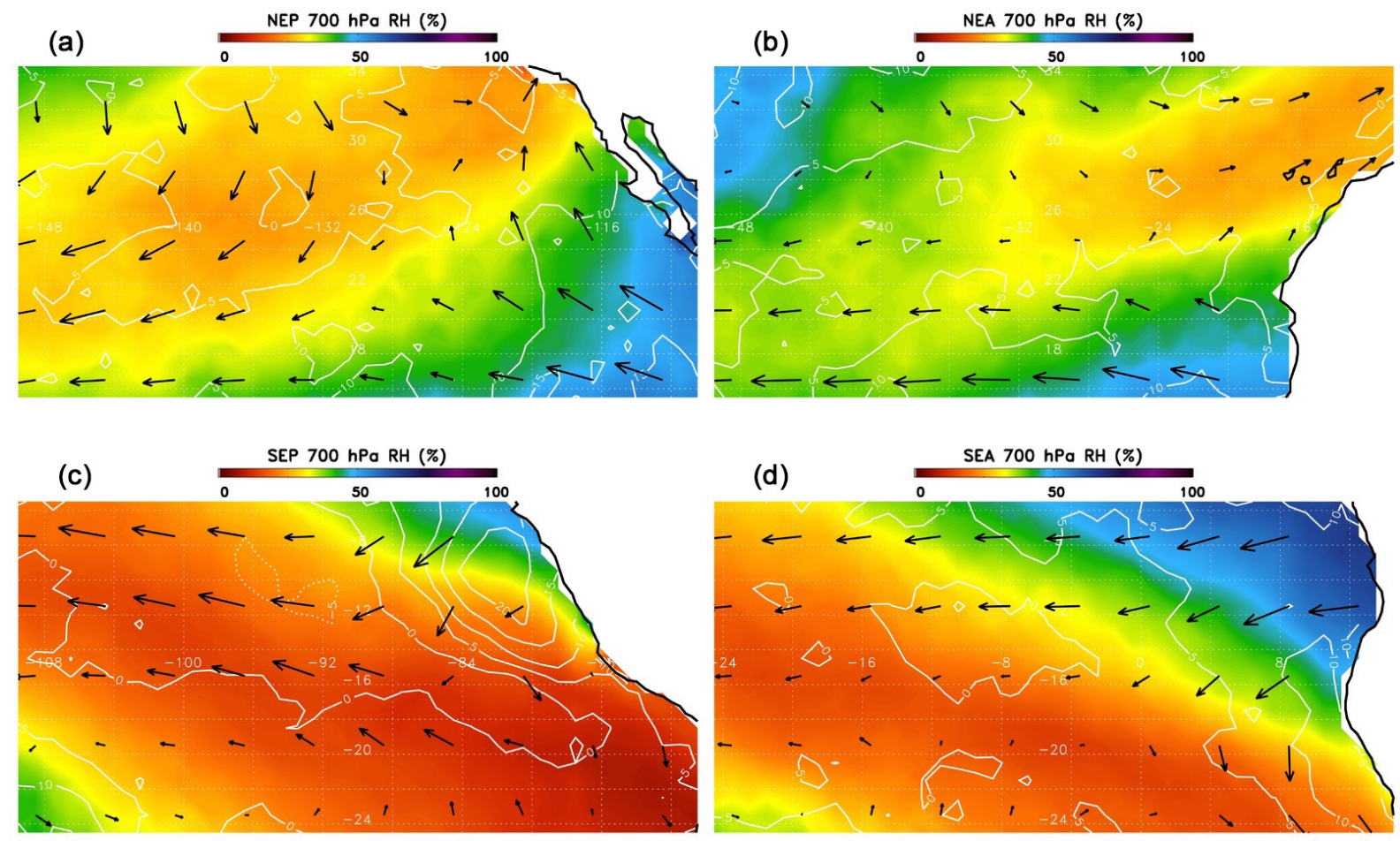

Figure 5. AIRS $\mathrm{RH}_{700}(\%)$ for regions listed in Table 1: (a) NEP, (b) NEA, (c), SEP, and (d) SEA. The MERRA-AIRS RH700 difference is shown as white contours (solid implies MERRA is moister, and dashed implies AIRS is moister). The length and direction of the arrows depict the $700 \mathrm{hPa}$ wind vectors from MERRA.

and water vapor weighting function widths on the order of 2-3 km (Maddy and Barnet, 2008).

In summary, the seasonal averages exhibit realistic threedimensional spatial morphologies and gradients and show consistency with MERRA RH in the subtropical MBL. The MBL depth and seasonal variations (not shown) agree with GPS-RO (Chan and Wood, 2013). The AIRS-derived dMSE between 700 and $1000 \mathrm{hPa}$ agrees with ERA-Interim (Kubar et al., 2012). The radiance skewness is strongly related to dMSE (Kawai and Teixeira, 2012). The AIRS ECF distributions closely correspond to well-established climatologies of cloud amount (e.g., Klein and Hartmann, 1993; Rossow and Schiffer, 1999; Wood, 2012). The vertical structure of the horizontal wind flow well represents known climatological patterns in the MBL and lower free troposphere. While the variability within each region and between the four regions is consistent with previous studies, the physical reasons for these differences are beyond the scope of the current investigation.

\section{Multivariate and multimoment PDFs}

\subsection{Dimensionality of PDFs}

Choosing an ideal subset of variables and statistical moments to form the basis of joint histograms is a challenge. Motivated in large part to link cloud and thermodynamic properties derived from infrared and visible bands, we describe six variable combinations. The natural log frequency of occurrence is shown in gray scale from black to white, and MBL depth is superimposed as contours (Fig. 7).

The MBL depth exhibits clearer patterns in the ECF dimension (Fig. 7a, c) rather than the cloud fraction dimension (Fig. 7b, d). The latter is more compressed, and the gradients are weaker in both dimensions. The MBL depth is deepest for lower values of ECF, $\tau$, and visible radiance. In addition, the MBL depth also decreases for the most reflective clouds at a given value of ECF, while this behavior is not observed for $\tau$. An additional population of subpixel cumulus clouds is captured within the radiance data that is not captured in $\tau$ data. The two other panels (Fig. 7e, f) highlight the challenges with the choice of dimensionality. In the case of radiance versus $\tau$, while there is a strong correlation in the occurrence frequency within the more reflective clouds, the structure in the MBL depth is much less clear. In the case of cloud fraction versus ECF, the occurrence frequency is much more poorly correlated and scattered, while the MBL depth shows less structure in either dimension.

We will use radiance versus ECF (Fig. 7a) in the remainder of this work. We are not advocating that the dimensional choices made are optimal. Instead, the results motivate the use of satellite and reanalysis data building from 

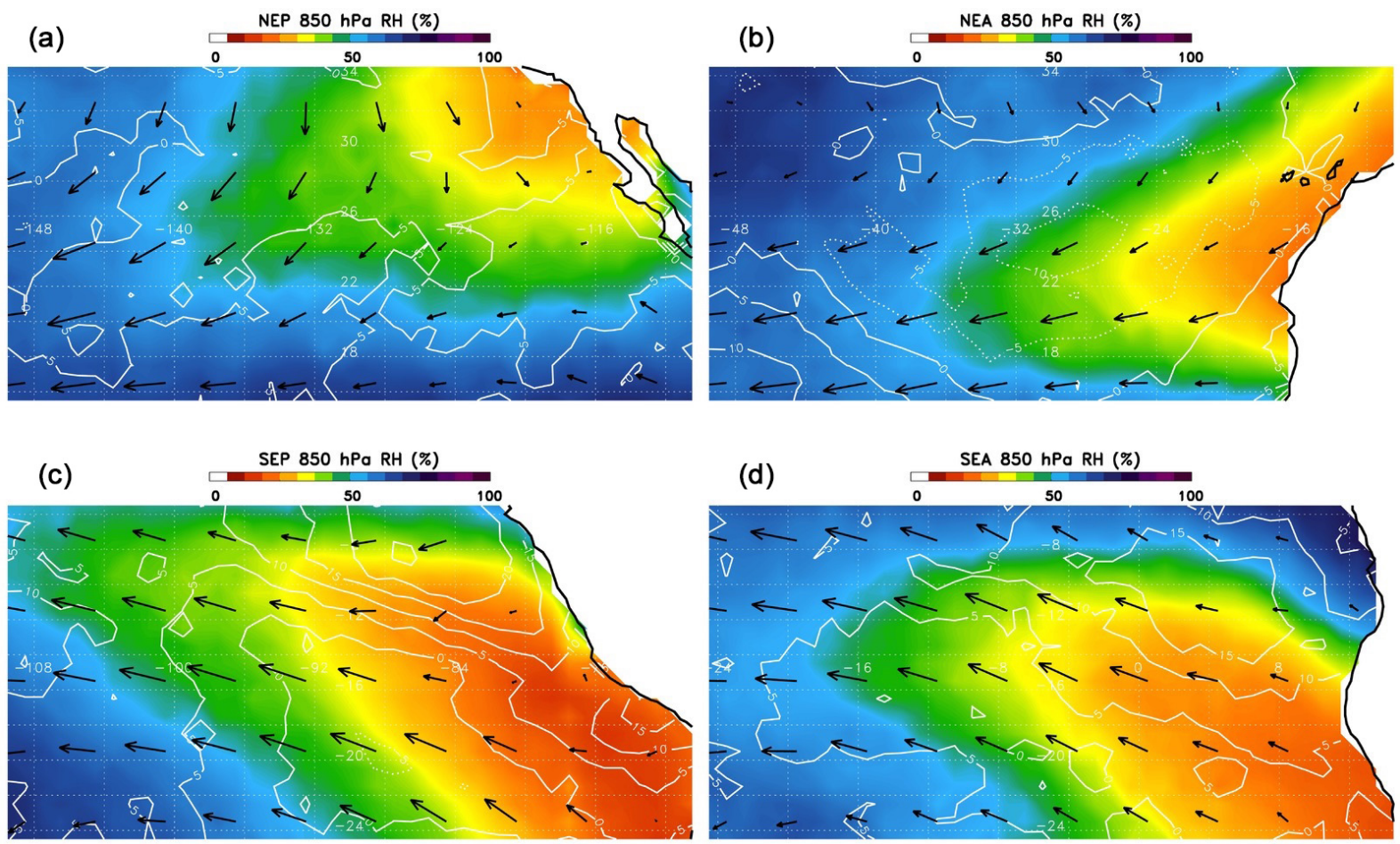

Figure 6. AIRS $\mathrm{RH}_{850}(\%)$ for regions listed in Table 1: (a) NEP, (b) NEA, (c), SEP, and (d) SEA. The MERRA-AIRS RH 850 difference is shown as white contours (solid implies MERRA is moister, and dashed implies AIRS is moister). The length and direction of the arrows depict the $850 \mathrm{hPa}$ wind vectors from MERRA.

native-resolution, pixel-scale, temporally instantaneous coincidences.

\subsection{Regional similarity in MBL depth}

The frequencies of AMSU FORs that contain stratocumulus and cumulus are listed in Table 1. The largest differences in the gradients between stratocumulus and cumulus are found in the NEP (Fig. 8a, e), while the smallest differences are found in the NEA (Fig. 8c, g). The MBL depth is several tens of hectopascals shallower in stratocumulus (Fig. 8a-d) than in cumulus (Fig. 8e-h) in all four regions for almost every possible combination of radiance and ECF. We can conclude that the cloud amount and shortwave reflected radiation act independently of MBL depth. A small population of shallow MBL depths for ECF $>0.9$ is found in cumulus (Fig. 8eh) and is a consequence of a few stratocumulus clouds that fail to exhibit a large enough $T_{\mathrm{b}}$ signature to trigger liquid phase tests (e.g., Kahn et al., 2011, 2014). The two cloud regimes therefore should not be considered mutually exclusive of each other.

A significant increase in MBL depth with increasing radiance is found in cumulus with a stronger relationship in the $\mathrm{NH}$ than in the SH (Fig. 8e-h) at a fixed value of ECF. This is partly a result of a deeper MBL in the SEP and SEA near the coastline (Fig. 4). The exception is that the NEP, SEP, and SEA show a decrease for the most reflective clouds ex- cept for the NEA. Generally speaking the NEA is the largest outlier of the four regions for all radiance moments shown for MBL depth in Fig. 8 and is affected more by the midlatitudes than other regions. The MBL depth gradients have an approximately linear relationship with the standard deviation of radiance (Fig. 8i-1) unlike the average radiance (Fig. 8eh). The MBL is deepest for the largest values of the standard deviation at almost all values of ECF in all four regions. This suggests that the largest values of average radiance in Fig. 8e-h are uniform in spatial structure and have some of the lowest standard deviations (Fig. 8e-h).

The radiance skewness is shown in Fig. 8m-p. There are several important features to describe. First, the MBL depth is shallower for normally distributed radiance, and a sharp increase in MBL depth with increasing positive skewness is consistent with Figs. 3 and 4. Second, the change in MBL depth is somewhat greater for an identical increase in radiance skewness when compared to $\tau$ skewness (not shown). Third, the cumulus occurrences at low ECF for positive skewness $>1$ are mostly absent in the $\tau$ data (not shown) but are very common in radiance data. We argue that this discrepancy has an important impact on the interpretation of the trade cumulus climatology. The gradient of MBL depth in the dimension of increasing positive skewness at low values of ECF is much greater in the radiance data where the highest data counts are found. We posit that the radiance 

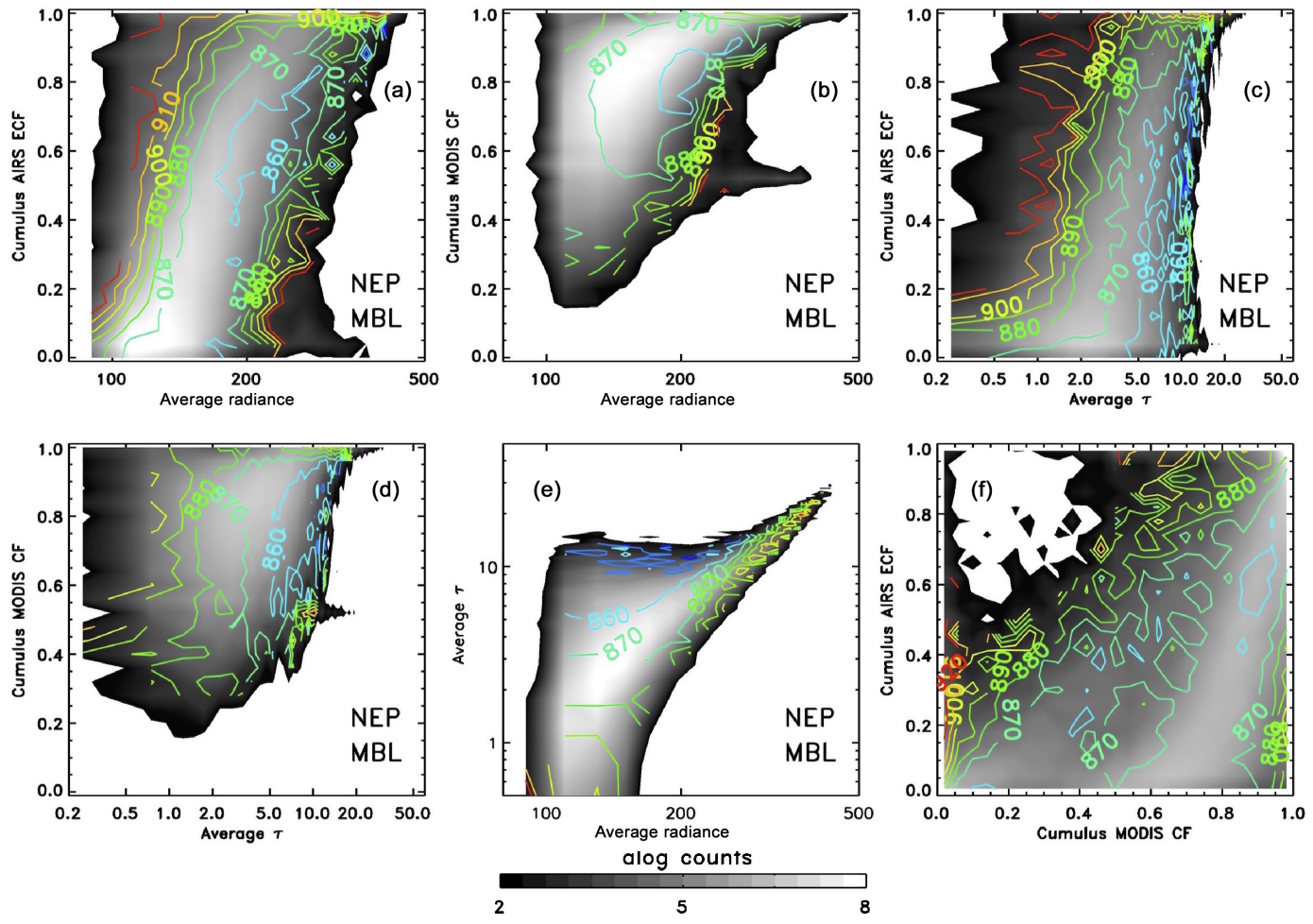

Figure 7. Shown are joint PDFs for six different combinations of variables that are described in Sect. 4.2: (a) radiance versus AIRS ECF, (b) radiance versus MODIS CF, (c) MODIS $\tau$ versus AIRS ECF, (d) MODIS $\tau$ versus MODIS CF, (e) radiance versus MODIS $\tau$, and (f) MODIS CF versus AIRS ECF. The gray scale is the natural $\log$ of total counts per bin. All values in the PDFs shown are for the cumulus regime. The color contours depict the MBL depth (hPa).

data contain more subpixel cumulus, which is missing in the $\tau$ data. Fourth (not shown), the AIRS cloud mask filter (Fig. 1b) is removed in order to retain all values of radiance (clear and cloudy) in the joint PDF. While the patterns of radiance skewness and MBL depth are not significantly altered when applying the cloud mask filter, many more counts with normally distributed radiances appear, which indicates some leakage of weak clear-sky surface reflection. We conclude that there is a much bigger difference between the cloudmask-filtered radiance and $\tau$ than between the filtered and non-filtered variants of radiance, implying a robust interpretation. Fifth, the MBL depth contours change more rapidly with skewness of $\tau$ or radiance than with the mean value of $\tau$ or radiance, consistent with the findings of Kawai and Teixeira (2010), where a tighter correlation with LWP skewness compared to average LWP was found.

Figure 9 shows that the dMSE in the SEP is positive in sign and largest in magnitude for larger values of ECF and normally distributed radiance (other regimes are similar and are not shown). In the case of radiance skewness, contours of constant dMSE track closely to the occurrence frequency through much of the joint PDFs, with a reduction of dMSE to values less than 0 at a fixed value of ECF as positively skewed radiances increases. This behavior is similar to MBL depth (Fig. 8f) and suggests that instantaneous values of
dMSE correlate well with small-scale cloud variability. This is not inconsistent with LTS and dMSE correlating well with larger-scale atmospheric thermodynamic structure on much longer timescales. Kawai and Teixeira (2012) showed that the skewness of LWP varies from +1 to +2 for cloud amounts of $90-100 \%$, and up to +1.5 to +3.5 for cloud amounts $<30 \%$. Kawai and Teixeira (2010) showed that the highest correlations are found between LWP homogeneity, skewness, and kurtosis with temperature and moisture differences between the surface and $850 \mathrm{hPa}$; the correlations to EIS and LTS were not as large.

\subsection{Relating meteorology and microphysical processes}

Nuijens et al. (2009) describe RICO field campaign observations that illustrate fundamental physical relationships between cloud cover, wind speed and direction, the vertical structure of $\mathrm{RH}$, and precipitation frequency and intensity within precipitating shallow trade cumulus. The observations can be grouped into three fairly distinct cumulus regimes: (i) low cloud fraction with little to no precipitation characterized by low values of $u$ and a drier MBL; (ii) an increase in cloud fraction with some light precipitation characterized by low values of $u$ and elevated RH between 800 and $1000 \mathrm{hPa}$; and (iii) a further increase in cloud fraction with 

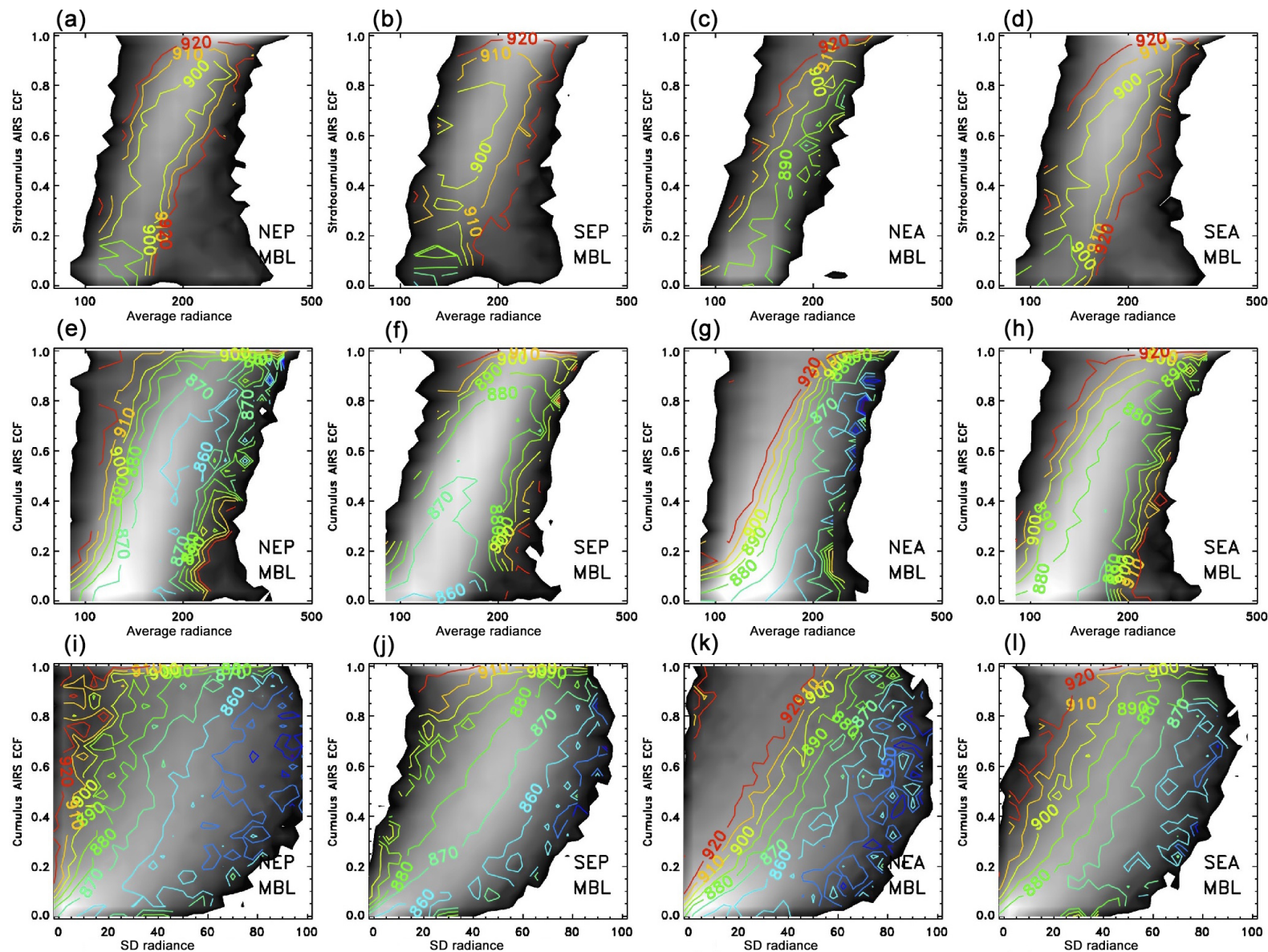

(k)
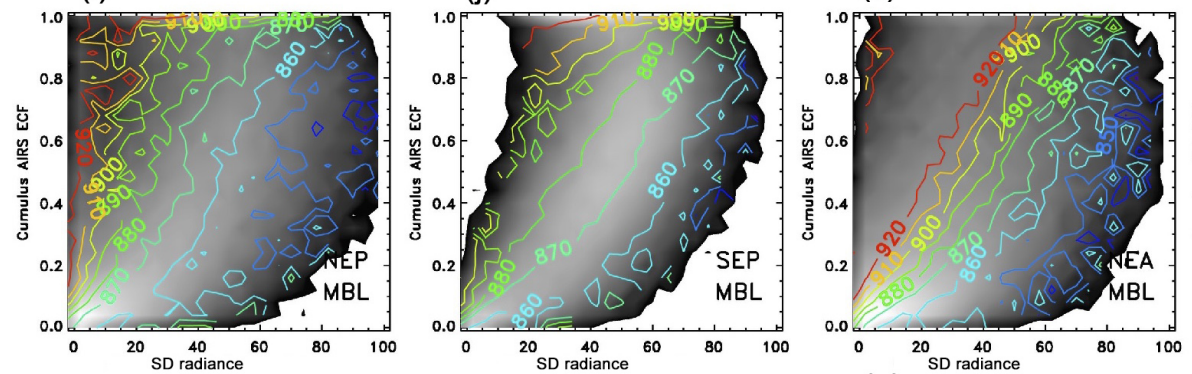

(I)
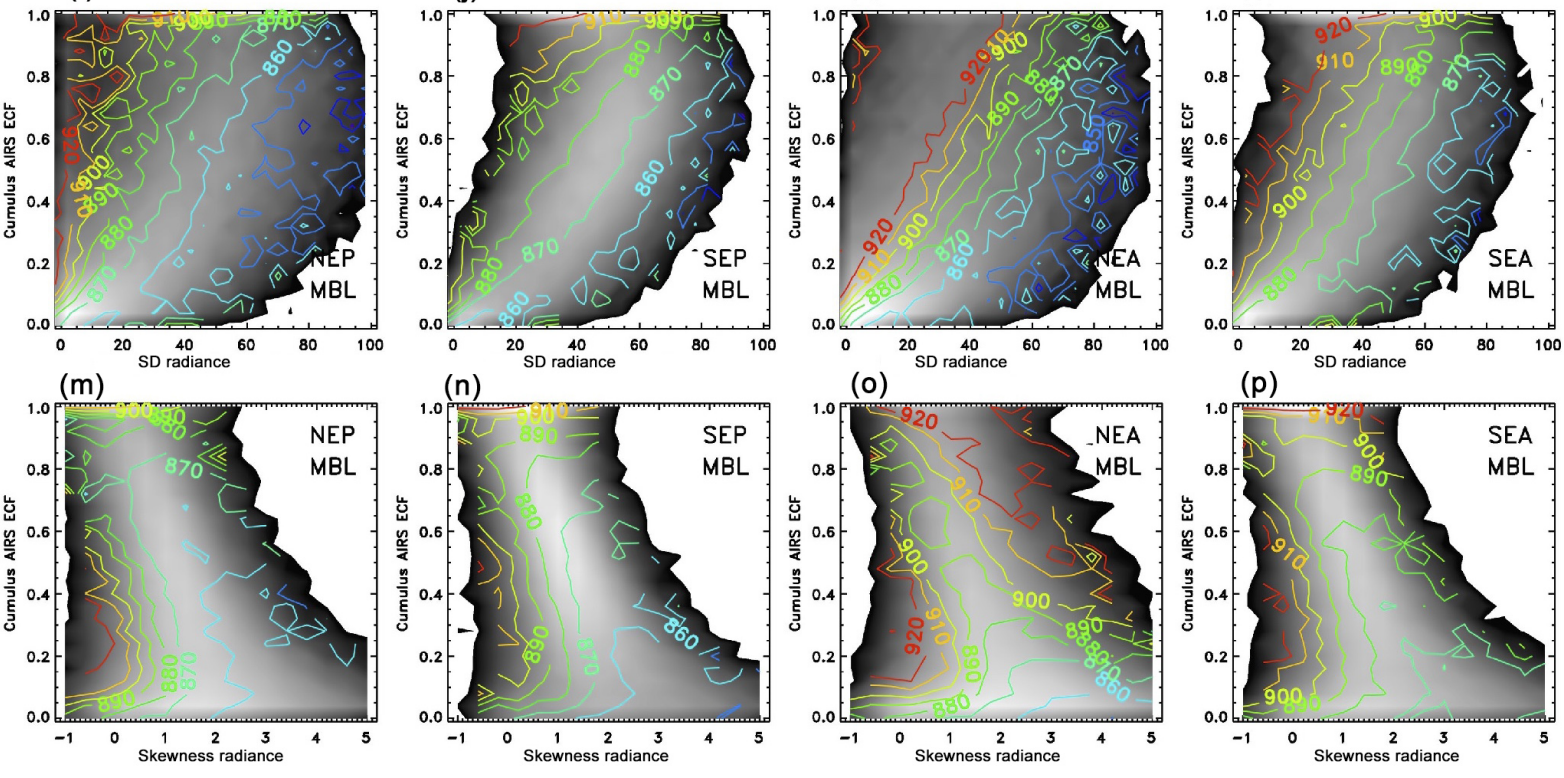

(p)
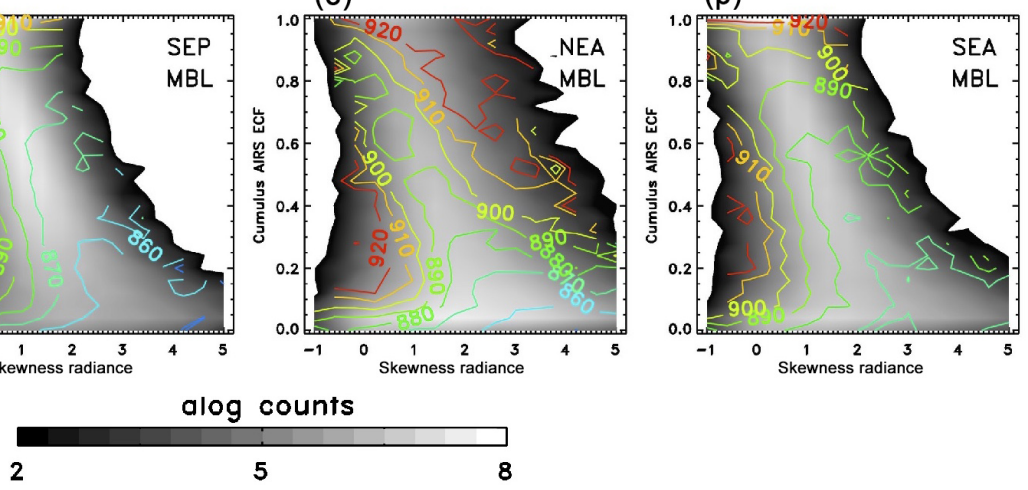

Figure 8. Joint PDFs of visible radiance versus ECF for the four spatial regions listed in Table 1. The SEP in Fig. 7 is repeated here for clarity.

light precipitation and some isolated heavier events characterized by higher values of $u$ and a large increase in RH between 650 and $900 \mathrm{hPa}$. A key observational difference among the three regimes is the variation of $\mathrm{RH}$ within the MBL (800-1000 $\mathrm{hPa}$ ) and near the top of the MBL extending into the lower free troposphere $(650-900 \mathrm{hPa})$. The width of these layers is similar to the AIRS 700 and $925 \mathrm{hPa}$ temperature and specific humidity weighting functions. Even though the RICO observations do not fall within any of the four re- gions listed in Table 1, Medeiros and Nuijens (2016) show that the observational site is applicable to the trade regime as a whole across the globe. Thus our approach for the remainder of the investigation is to determine if similar relationships shown in Nuijens et al. (2009) exist in cumulus for the regions listed in Table 1.

Figure 10 shows the MODIS-derived $r_{\mathrm{e}}$ for stratocumulus (Fig. 10a-d) and cumulus (Fig. 10e-p) that are limited to successful retrievals (no PCL pixels are included). There 


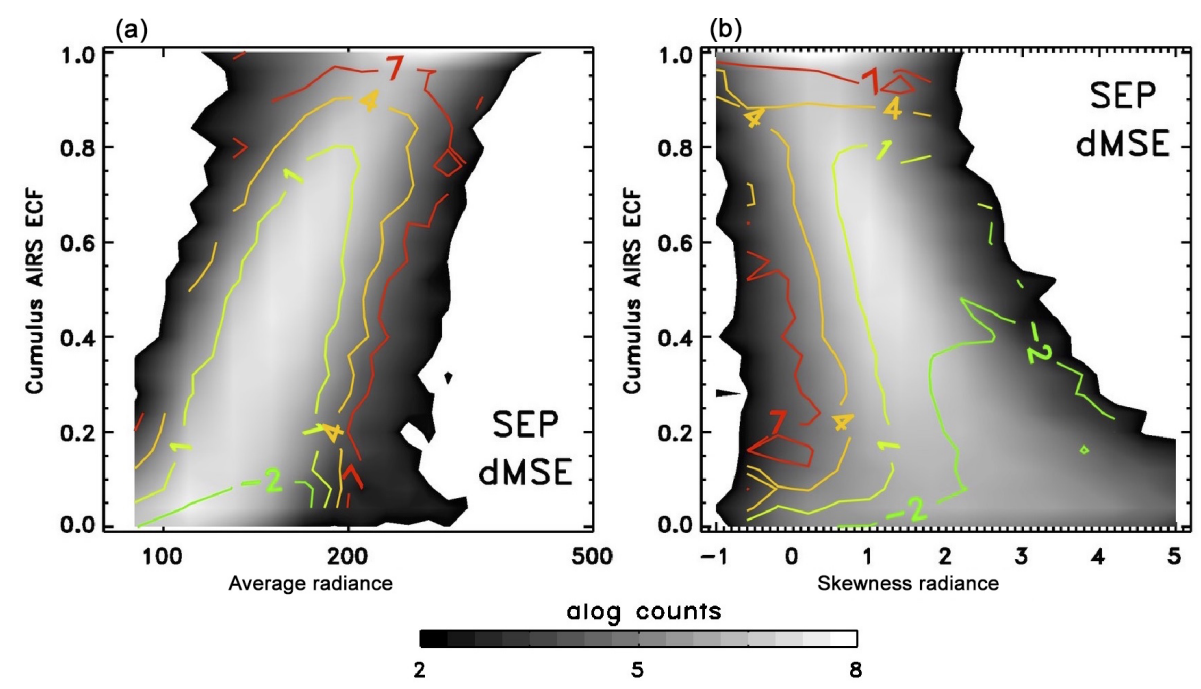

Figure 9. Joint PDFs of visible radiance average (left) and skewness (right) versus ECF for the SEP with dMSE depth as the overlay field. Other regions are very similar and are not shown for reasons of brevity.

are several prominent features in the histograms. First, the stratocumulus $r_{\mathrm{e}}$ is about 11 to $12 \mu \mathrm{m}$ throughout most of the PDF in all four regions. An exception is the increase of $r_{\mathrm{e}}$ by several micrometers when average radiance and ECF are reduced (Fig. 10a-d). While these particular MODIS pixels were successful, cloud horizontal inhomogeneity causes larger $r_{\mathrm{e}}$ within this population of clouds because of the plane-parallel homogeneous bias (Cho et al., 2015; Zhang et al., 2016). Cloud inhomogeneity may also lead to significant 3-D radiative transfer effects, but these tend to cause both larger and smaller $r_{\mathrm{e}}$ in similar proportions (Zhang et al., 2012). Second, the NEA region (Fig. 10g) is most dissimilar to the other three regions for average (Figs. 10e-h), standard deviation (Fig. 10i-1), and skewness (Fig. 10m-p). Third, $r_{\mathrm{e}}$ is largest along the axis of maximum counts with values upwards of 16 to $20 \mu \mathrm{m}$ in the SEP, $15-18 \mu \mathrm{m}$ in the SEA, and $14-17 \mu \mathrm{m}$ in the NEP. The largest values in the NEA are confined to the most skewed radiances unlike the other three regions. Fourth, in the cleaner SH, the values of $r_{\mathrm{e}}$ appear to be more tightly coupled to cloud microphysical processes that respond to changing wind speed and a deepening MBL. Fifth, the variations of $r_{\mathrm{e}}$ with the standard deviation of radiance (Fig. 10i-1) are more nonlinear than in the case of MBL depth (Fig. 8i-1). This shows that the relationship between radiance moments and different physical quantities is not the same.

One general interpretation of the larger $r_{\mathrm{e}}$ in cumulus (Fig. 10e-h) than in stratocumulus (Fig. 10a-d) is that it is caused by increased inhomogeneity of cumulus (Zhang et al., 2012), retrieval failures and partly cloudy pixels (Cho et al., 2015), and view angle biases (e.g., Liang et al., 2015) that are further coupled together with other factors at play (Zhang et al., 2016). The aforementioned issues may still impact a successful $r_{\mathrm{e}}$ retrieval. However, we offer evidence that the increase in $r_{\mathrm{e}}$ is also consistent with environmental variability, which in turn is consistent with droplet growth and precipitation. The contours of $r_{\mathrm{e}}$ correspond very closely to the magnitude of the $u$ component of wind speed at $925 \mathrm{hPa}$ ( $\left.u_{925}\right)$ (see Fig. 12) and other levels in the MBL (not shown), suggesting a link between cloud droplet growth, light rain, and dynamical variability. The somewhat larger $r_{\mathrm{e}}$ in the $\mathrm{SH}$ is consistent with droplet growth in a cleaner environment (Suzuki et al., 2010a, b). Successful retrievals may be more frequently precipitating, either because of larger $r_{\mathrm{e}}$ in the cloud or because the plane-parallel homogeneous bias is larger in precipitating clouds.

To determine if the elevated $r_{\mathrm{e}}$ along the axis of maximum counts is associated with increased precipitation frequency, collocated matchups of the CloudSat precipitation rate are used to determine which AMSU FOVs contain occurrences of precipitation. Figure 11 shows results for the SEP region. The radiance skewness for the full AIRS/AMSU/MODIS swath in Fig. 10n is restricted to the CloudSat ground track in Fig. 11a. The counts are reduced by a factor of $\sim 30$ as expected. There are some subtle changes in the $r_{\mathrm{e}}$ distribution showing an increase of 2-3 $\mu \mathrm{m}$ with increasing skewness at a fixed value of ECF. Figure 11b shows the proportion of the PDF that contains at a minimum the natural $\log (2)$ counts of precipitation occurrence within each bin. About 20-50\% of the AMSU FOVs are precipitating according to CloudSat within the PDF of Fig. 11a. The precipitation frequency is consistent with Rapp et al. (2013), where up to $40 \%$ of clouds precipitate in the cumulus regime. Little to no precipitation occurs outside of the central portion of the PDF in Fig. 11a. The highly skewed cumulus with $\mathrm{ECF}<0.2$ appears to be exhibiting large $r_{\mathrm{e}}$ biases due to visible radiance inhomogeneity (Cho et al., 2015; Zhang et al., 2016). We also point out that the population of clouds detected by CloudSat 
(a)

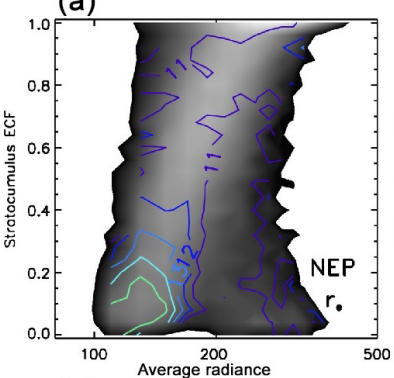

(e)

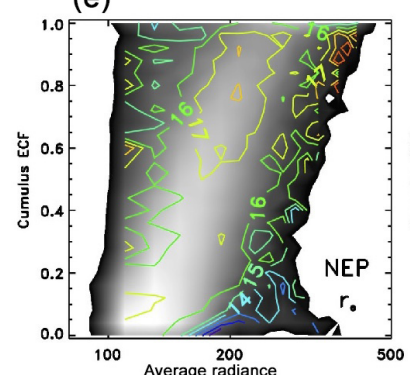

(i)

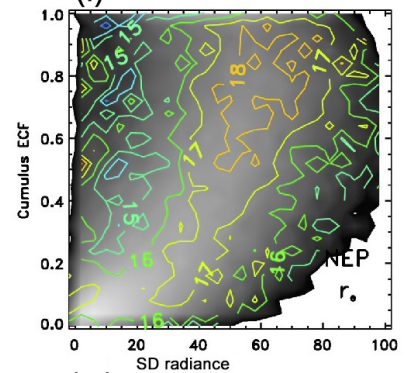

(m)

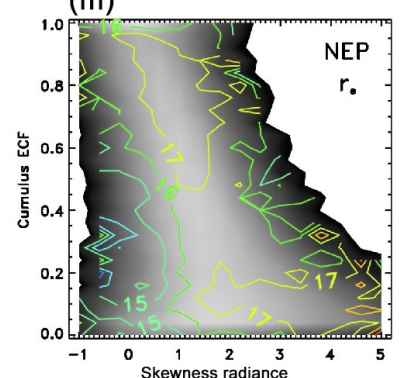

(b)

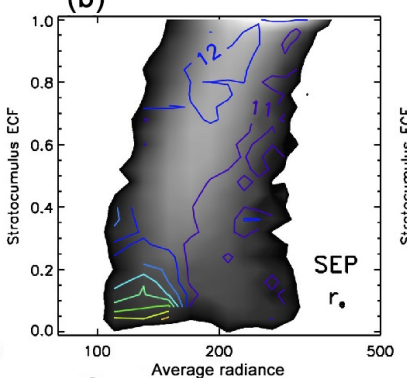

(f)

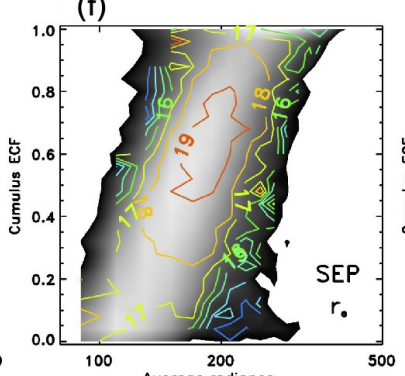

(j)

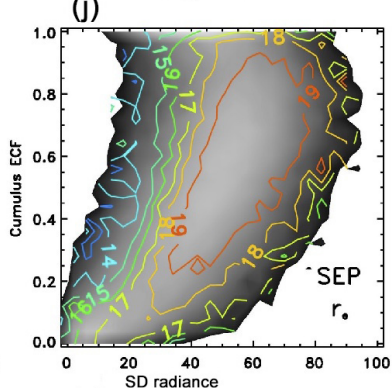

(n)

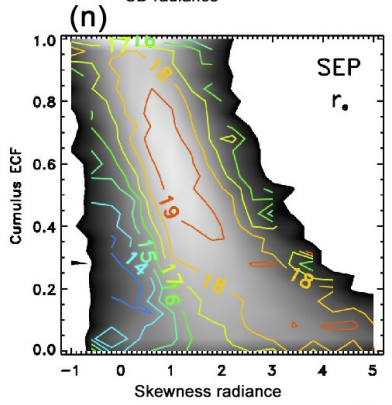

(c)

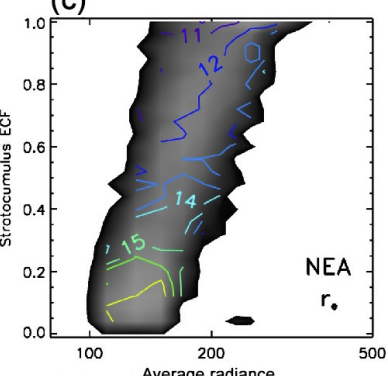

(g)

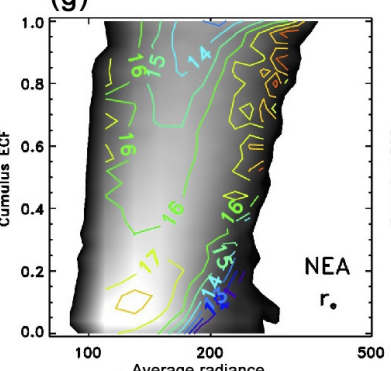

(k)

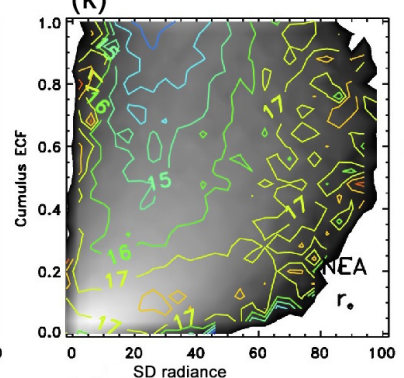

(o)

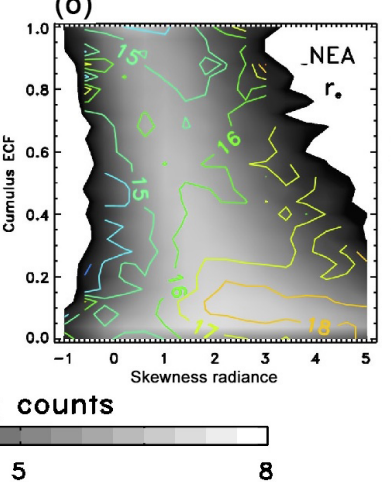

5 (d)

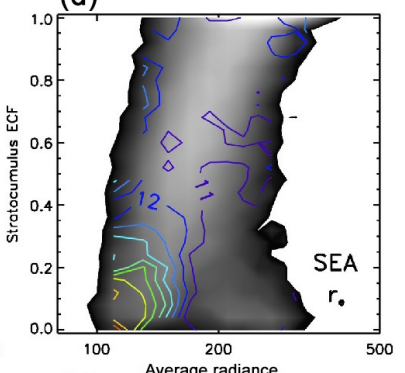

(h)

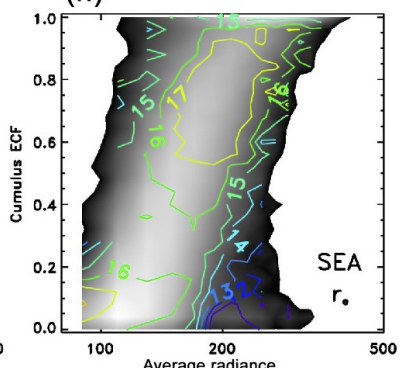

(I)

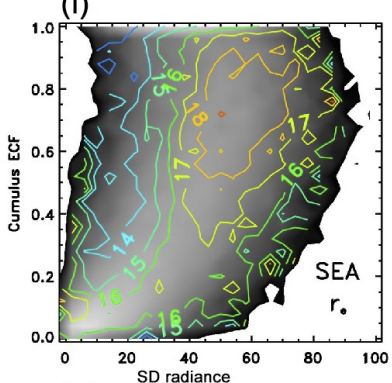

(p)

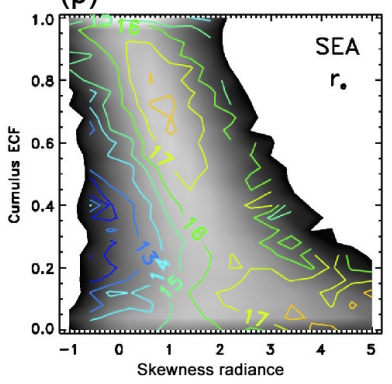

Figure 10. Joint PDFs of visible radiance skewness versus ECF for the four regions listed in Table 1; the overlay field is $r_{\mathrm{e}}$.

that have ECF $>0.95$ (Fig. 11b) is associated with very little precipitation and is consistent with the spatial distributions described by Rapp et al. (2013).

Figure 12 shows $\theta_{\mathrm{e}, 700}, u_{925}, \omega_{700}$, and $\omega_{925}$. The $\theta_{700}$ (not shown) is nearly identical among all regions with $\theta_{700}=314 \mathrm{~K} \pm 1 \mathrm{~K}$. Thus, the structure in $\theta_{\mathrm{e}, 700}$ (Fig. 12ad) is driven by variations in specific humidity. For a fixed value of ECF, the clouds with the lowest and highest values of radiance are associated with moistening of the lower free troposphere. Using climatological averages, Myers and Nor- ris (2015) show that shortwave observations from CERES, cloud fraction estimates from ISCCP and CALIPSO, and $\mathrm{RH}_{700}$ and $\omega_{700}$ from ERA-Interim reflect aspects of Fig. 12 and, namely, that more reflected shortwave is associated with increased cloud fraction and decreased $\omega_{700}$.

The highest values of $\theta_{\mathrm{e}, 925}$ (not shown) occur along the axis of highest counts, while reductions in $\theta_{\mathrm{e}, 925}$ occur for the least and most reflective clouds at a fixed value of ECF. This is the case for the NEP, SEP, and SEA, but the NEA is an outlier and shows a constant increase as seen with RH 

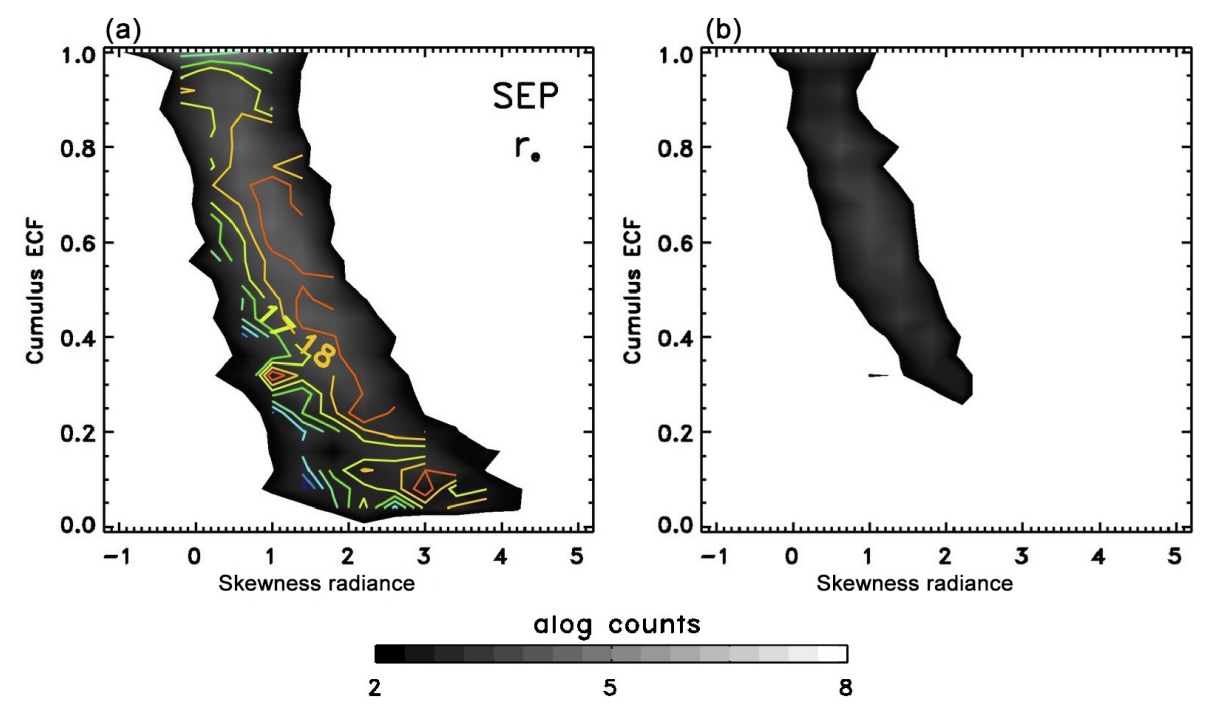

Figure 11. (a) Same as Fig. 10n except that sampling is restricted to AMSU FORs that contain the CloudSat ground track. (b) Samples of the data in (a) that contain detected precipitation according to CloudSat.

and MBL depth. Unlike $700 \mathrm{hPa}, \theta_{925}$ is more variable (not shown) between the four regions but is generally $2 \mathrm{~K}$ or less.

The $u_{925}$ is largest (Fig. 12e-h) when the PDF has the largest counts and very closely resembles $r_{\mathrm{e}}$ in Fig. 10e-h. The subtle differences in the contours in Figs. 10e-h and $12 \mathrm{e}-\mathrm{h}$ align very well, suggesting a tight correlation between the two parameters. The magnitude of $u_{925}$ is larger than $u_{700}$ (not shown), consistent with RICO (Nuijens and Stevens, 2009). The $\omega_{700}$ fields (Fig. 12i-l) exhibit minimal correspondence with average radiance and ECF in the $\mathrm{NH}$ regimes with a weak correspondence in the average radiance in the SH regions. The $\omega_{925}$ fields (Fig. 12m-p) show larger gradients in all four regions. The $\omega_{925}$ decreases with increasing radiance in all regions similar to that shown in Myers and Norris (2015), with a slightly noisier pattern in $\omega_{925} \mathrm{ob}-$ served in the NH regimes. The decrease of $\omega_{925}$ with increasing radiance is consistent with a deeper MBL (Fig. 8e-h) and larger $\tau$. Where $u_{925}$ (Fig. 12e-h) increases, $\omega_{925}$ (Fig. $12 \mathrm{~m}-$ p) decreases and $\mathrm{RH}_{925}$ increases (not shown). The largest values of $r_{\mathrm{e}}$ (Fig. 10e-h) also correspond to the above tendencies, consistent with the concept of more frequent precipitating clouds within a windier and deeper MBL (Nuijens and Stevens, 2012).

The joint PDFs imply simultaneous increases in $\theta_{\mathrm{e}, 700}$, $\theta_{\mathrm{e}, 925}$ (and by extension $\mathrm{RH}_{700}$ and $\mathrm{RH}_{925}$ ), $u_{925}$, and ECF in three of the four regions investigated (NEP, SEP, and SEA) with a particularly strong relationship between $u_{925}$ and $r_{\mathrm{e}}$. The NEA is somewhat of an outlier, although this is based on one season's worth of data during 2009. There is much variability across the trade cumulus regime as it should not be treated as a single homogeneous entity.

\section{Summary and conclusions}

The global-scale relationships and coupling of cloud fraction and spatial variability to thermodynamic and dynamic properties of the atmosphere remain poorly understood (Bony et al., 2015). The NASA A-train (Stephens et al., 2002) provides a wealth of remote-sensing data about the microphysics and thermodynamics of the cloudy MBL. MERRA (Rienecker et al., 2011) offers a complementary set of thermodynamic and dynamic variables that helps establish context for coincident remote-sensing observations. The synergy between satellite and reanalysis data at the native spatial and temporal resolutions available has not been fully exploited to date. We describe a new approach that leverages coincident reanalysis and remote-sensing data at the native resolution of the observations. The spatial variability of clouds, and the relationship to thermodynamic and dynamic state variables, is thus inferred using the finest temporal and spatial resolutions available.

Four subtropical oceanic regions that capture transitions from stratocumulus to trade cumulus are investigated. We define two regimes based exclusively on liquid and unknown cloud thermodynamic phase detections with the AIRS instrument, and we generically refer to them as stratocumulus and cumulus regimes, respectively. The mean, standard deviation, and skewness of MODIS and AIRS FOV cloud properties and visible radiances are calculated for each AIRS and MERRA temperature and humidity observation.

As with previous findings, coastal stratocumulus radiances are approximately normally distributed, while the radiances are positively skewed away from the coast, where disorganized cumulus dominates. The radiance skewness closely aligns with the magnitude of AIRS ECF in cumulus with 

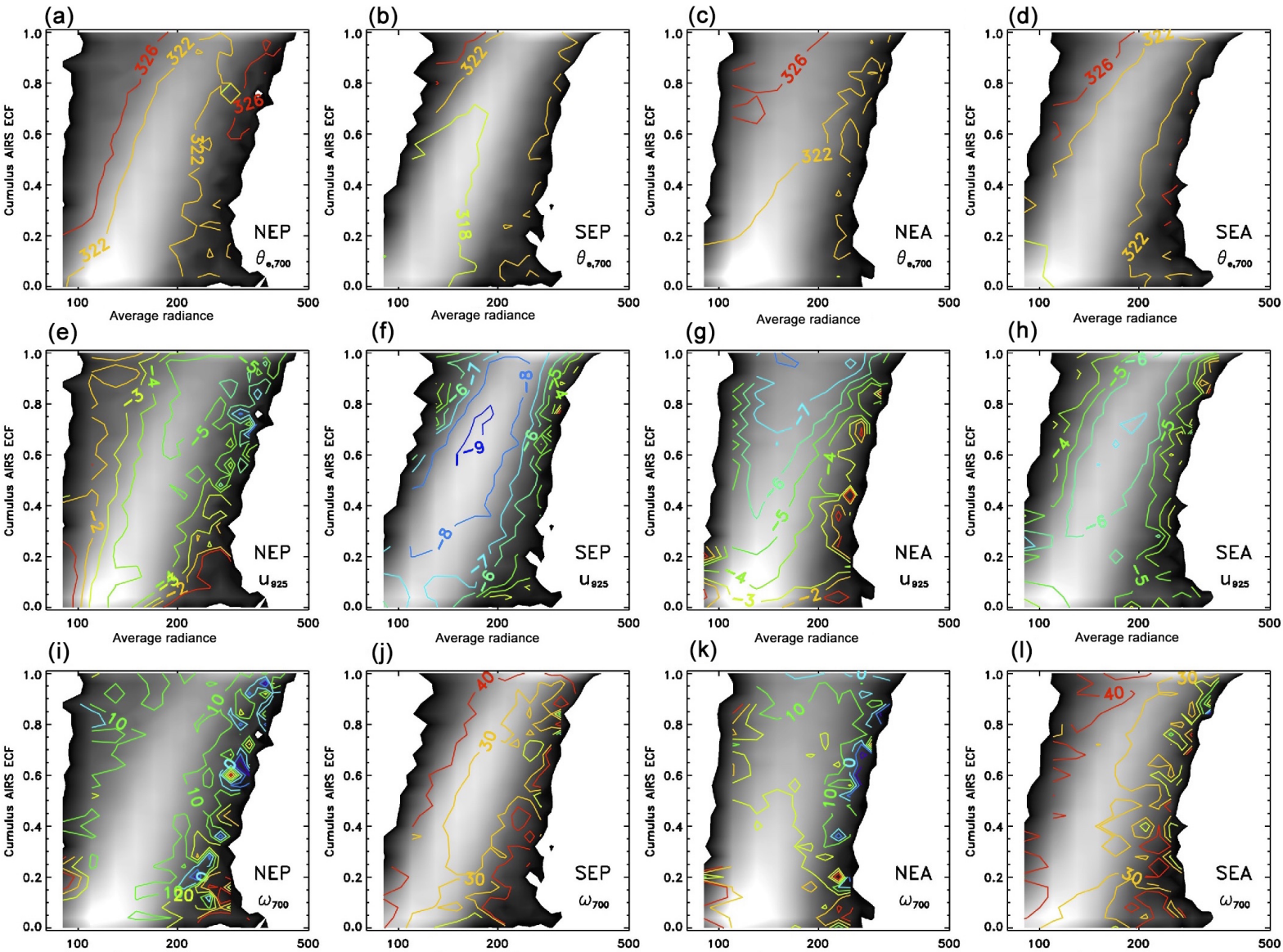

(k)

(I)
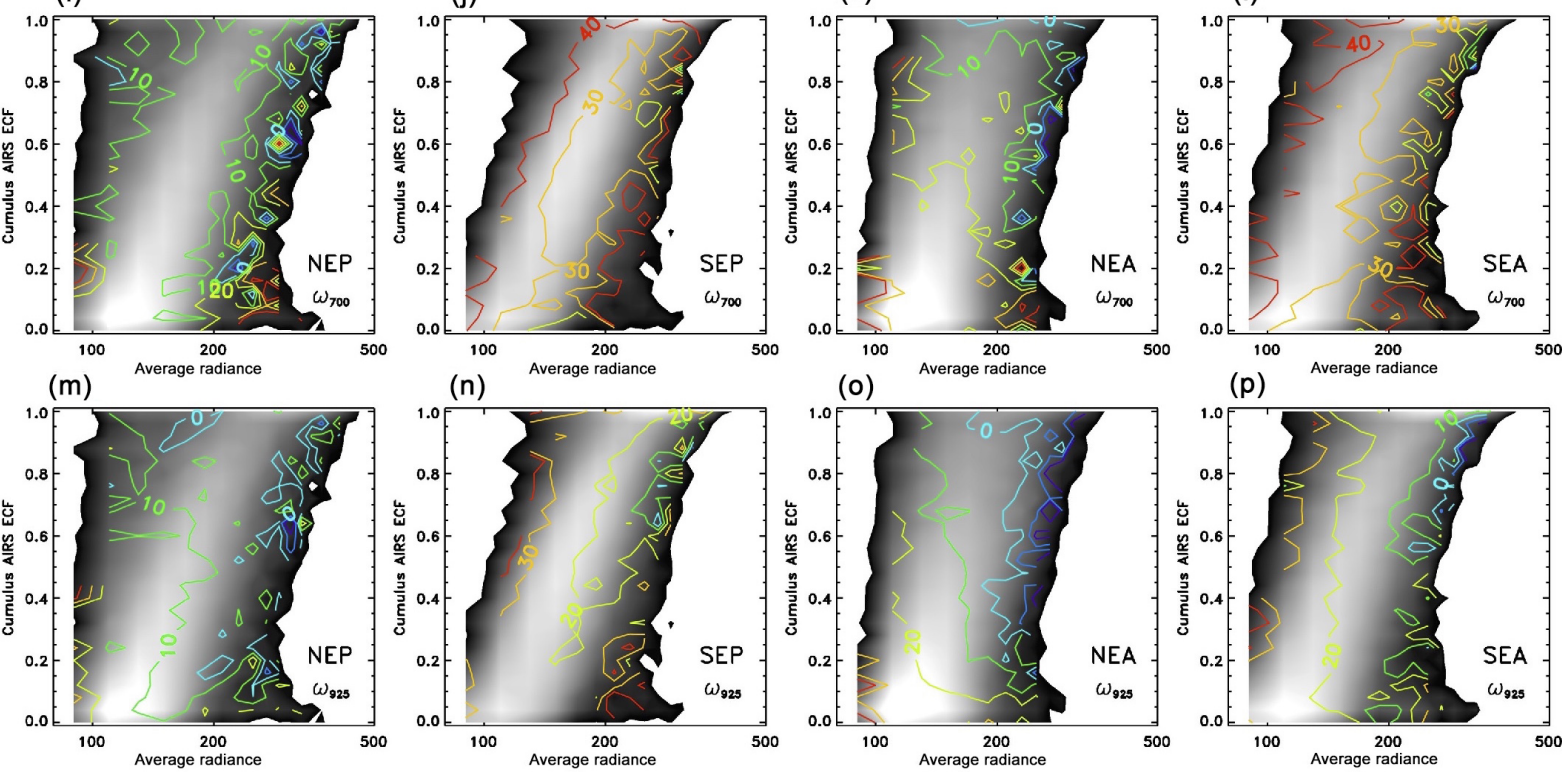

(0)

(p)
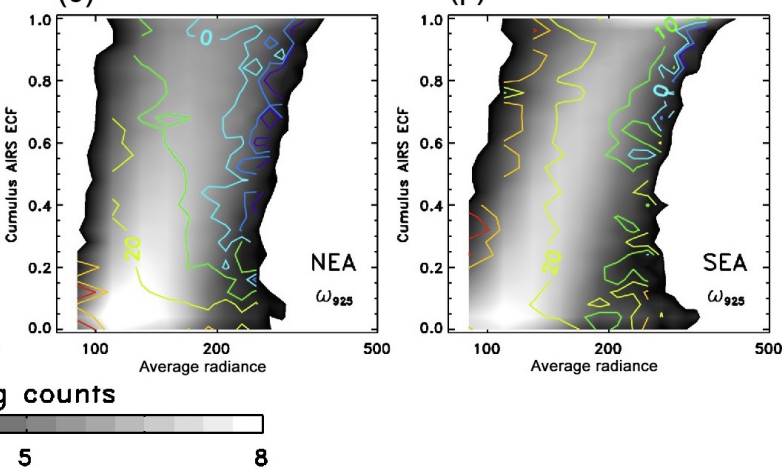

Figure 12. Joint PDFs of $700 \mathrm{hPa} \theta_{\mathrm{e}}, u_{925}, \omega_{700}$, and $\omega_{925}$ for the four regions listed in Table 1.

less correspondence in stratocumulus. Strong (poor) spatial correspondence between radiance skewness and AIRS ECF (MODIS cloud fraction) was found, suggesting infraredbased ECF is a potentially valuable and unappreciated diagnostic for MBL cloud characterization. The mean MBL depth derived from AIRS (Martins et al., 2010) shows a characteristic transition from shallow MBLs (920-970 hPa) near the coast to deeper MBLs (830-880 hPa) away from the coast and is a well-observed feature of the stratocumulus-tocumulus transition (e.g., Teixeira et al., 2011). The AIRSderived dMSE between 700 and $1000 \mathrm{hPa}$ agree very well with ERA-Interim (Kubar et al., 2012). We find that the radiance skewness is strongly related to the magnitude of dMSE as previously found by Kawai and Teixeira (2012). The MBL depth is shallower for stratocumulus than cumulus for almost all values of visible radiance and ECF.

The change in MBL depth is somewhat greater for an identical increase in radiance skewness when compared to $\tau$ skewness. The population of cumulus occurrences at low ECF for positive skewness $>1$ is mostly absent in the $\tau$ data but are very common in radiance data. This highlights the importance of understanding the sampling from derived 
Level 2 products compared to Level 1 radiances that may capture a fuller range of the geophysical state in different cloud regimes.

The $r_{\mathrm{e}}$ in stratocumulus is about 11 to $12 \mu \mathrm{m}$ for most values of radiance and ECF in all four regions of study. For cumulus, $r_{\mathrm{e}}$ ranges anywhere from 12 to $20 \mu \mathrm{m}$, with larger $r_{\mathrm{e}}$ for increasing positive skewness especially when ECF is small. The values of $r_{\mathrm{e}}$ appear to be tightly coupled to cloud microphysical processes that respond to changing MBL wind speed and a deepening MBL. We argue that for these successful MODIS retrievals the increase in $r_{\mathrm{e}}$ is consistent with increased droplet growth and hence precipitation occurrence. This may be caused by larger $r_{\mathrm{e}}$ in the cloud itself or by the association of precipitating clouds with an increased subpixel inhomogeneity that leads to the plane-parallel homogeneous bias; this topic warrants further investigation. In the SEP region, the elevated values of $r_{\mathrm{e}}$ that correspond with the increased $u_{925}$ are more frequently precipitating according to CloudSat.

The RICO observations provide an important multiparameter testing benchmark (Nuijens et al., 2009). These results are generalized into three types of shallow precipitating cumulus regimes observed during RICO. The joint PDFs imply simultaneous increases in $\theta_{\mathrm{e}, 700}, \theta_{\mathrm{e}, 925}, u_{925}$, and ECF in three of the four regions investigated (NEP, SEP, and SEA) with a strong correspondence between $u_{925}$ and $r_{\mathrm{e}}$. The NEA less clearly follows these behaviors and is an outlier, although this is based on one season's worth of data during 2009.

Future work will expand to other cloud regimes, additional data sets, and multiple years of data. A similar approach with numerical model output should also be attempted using temporal snapshots of similar geophysical fields. We expect that this approach will be especially useful for linking cloud microphysics together with the thermodynamic and dynamic state of the atmosphere at the process scale.

Data availability. The AIRS version 6 data sets were processed by and obtained from the Goddard Earth Services Data and Information Services Center (http://daac.gsfc.nasa.gov/). The MODIS Collection 6 data sets were processed by and obtained from the Level 1 and Atmosphere and Archive Distribution System (http: //ladsweb.nascom.nasa.gov). The MERRA data sets were processed by and obtained from the NASA Goddard Global Modeling and Assimilation Office (GMAO). CloudSat data were obtained through the CloudSat Data Processing Center (http: //www.cloudsat.cira.colostate.edu/). The data and code used in this investigation are available upon request from the lead author (brian.h.kahn@jpl.nasa.gov). All rights reserved. Government sponsorship acknowledged.

Competing interests. The authors declare that they have no conflict of interest.
Acknowledgements. Part of this research was carried out at the Jet Propulsion Laboratory (JPL), California Institute of Technology, under a contract with the National Aeronautics and Space Administration. Georgios Matheou and Brian H. Kahn were partially supported by an R\&TD project at JPL. Brian H. Kahn was partially supported by the AIRS project at JPL and by the NASA Science of Terra and Aqua program under grant NNN13D455T. Brian H. Kahn, Qing Yue, and Mathias M. Schreier were partially supported by NASA's Making Earth Science Data Records for Use in Research Environments (MEaSUREs) program. The authors are grateful to two reviewers for comments and suggestions that led to an improved version of this paper.

Edited by: Johannes Quaas

Reviewed by: two anonymous referees

\section{References}

AIRS: AIRS Science Team/Joao Texeira, AIRS/Aqua L2 Standard Physical Retrieval (AIRS-only) V006, Greenbelt, MD, USA, Goddard Earth Sciences Data and Information Services Center (GES DISC), https://doi.org/10.5067/AQUA/AIRS/DATA202, 2013.

Aumann, H. H., Broberg, S., Elliott, D., Gaiser, S., and Gregorich, D.: Three years of Atmospheric Infrared Sounder radiometric calibration validation using sea surface temperatures, J. Geophys. Res., 111, D16S90, https://doi.org/10.1029/2005JD006822, 2006.

Bony, S. and Dufresne, J. L.: Marine boundary layer clouds at the heart of tropical cloud feedback uncertainties in climate models, Geophys. Res. Lett., 32, L20806, https://doi.org/10.1029/2005GL023851, 2005.

Bony, S., Stevens, B., Frierson, D. M. W., and Coauthors: Clouds, circulation and climate sensitivity, Nat. Geosci., 8, 261-268, https://doi.org/10.1038/ngeo2398, 2015.

Bretherton, C. S., Wood, R., George, R. C., Leon, D., Allen, G., and Zheng, X.: Southeast Pacific stratocumulus clouds, precipitation and boundary layer structure sampled along $20^{\circ} \mathrm{S}$ during VOCALS-REx, Atmos. Chem. Phys., 10, 10639-10654, https://doi.org/10.5194/acp-10-10639-2010, 2010.

Bretherton, C. S., Blossey, P. N., and Jones, C. R.: Mechanisms of marine low cloud sensitivity to idealized climate perturbations: A single-LES exploration extending the CGILS cases, J. Adv. Model. Earth Sys., 5, 316-337, https://doi.org/10.1002/jame.20019, 2013.

Brueck, M., Nuijens, L., and Stevens, B.: On the seasonal and synoptic time-scale variability of the North Atlantic trade wind region and its low-level clouds, J. Atmos. Sci., 72, 1428-1446, 2015.

Cahalan, R. F., Ridgway, W., Wiscombe, W. J., and Bell, T. L.: The albedo of fractal stratocumulus clouds, Month. Weather Rev., 51, 2434-2455, 1994.

Caldwell, P. M., Zhang, Y., and Klein, S. A.: CMIP3 subtropical stratocumulus cloud feedback interpreted through a mixed-layer model, J. Clim., 26, 1607-1625, 2013.

Chahine, M. T., Pagano, T. S., Aumann, H. H., and Coauthors: The Atmospheric Infrared Sounder (AIRS): Improving weather forecasting and providing new insights into climate, B. Am. 
Meteor. Soc., 87, 911-926, https://doi.org/10.1175/BAMS-87-7911, 2006.

Chan, K. M. and Wood, R.: The seasonal cycle of planetary boundary layer depth determined using COSMIC radio occultation data, J. Geophys. Res.-Atmos., 118, 12422-12434, https://doi.org/10.1002/2013JD020147, 2013.

Cho, H.-M., Zhang, Z., Meyer, K., Lebsock, M., Platnick, S., Ackerman, A. S., Di Girolamo, L., Labonnote, L. C., Cornet, C., Riedi, J., and Holz, R. E.: Frequency and causes of failed MODIS cloud property retrievals for liquid phase clouds over global oceans, J. Geophys. Res.-Atmos., 120, 4132-4154, https://doi.org/10.1002/2015JD023161, 2015.

Chung, D., Matheou, G., and Teixeira, J.: Steady-state largeeddy simulations to study the stratocumulus to shallow cumulus cloud transition, J. Atmos. Sci., 69, 3264-3276, https://doi.org/10.1175/JAS-D-11-0256.1, 2012.

Clement, A. C., Burgman, R., and Norris, J. R.: Observational and model evidence for positive low-level cloud feedback, Science, 325, 460-464, https://doi.org/10.1126/science.1171255, 2009.

Dal Gesso, S., Siebesma, A. P., and de Roode, S. R.: Evaluation of low-cloud climate feedback through single-column model equilibrium states, Q. J. Roy. Meteor. Soc., 141, 819-832, https://doi.org/10.1002/qj.2398, 2015.

Fasullo, J. T. and Trenberth, K. E.: A less cloudy future: The role of subtropical subsidence in climate sensitivity, Science, 338, 792795, https://doi.org/10.1126/science.1227465, 2012.

Fetzer, E. J., Lambrigtsen, B. H., Eldering, A., Aumann, H. H., and Chahine, M. T.: Biases in total precipitable water vapor climatologies from Atmospheric Infrared Sounder and Advanced Microwave Scanning Radiometer, J. Geophys. Res., 111, D09S16, https://doi.org/10.1029/2005JD006598, 2006.

Gautier, C., Shiren, Y., and Hofstadter, M. D.: AIRS/Vis Near IR instrument, IEEE Trans. Geosci. Remote Sens., 41, 330-342, 2003.

Ghate, V. P., Miller, M. A., and Zhu, P.: Differences between nonprecipitating tropical and trade wind marine shallow cumuli, Month. Weather Rev., 144, 681-701, 2016.

IPCC: Climate Change 2013: The Physical Science Basis. Contribution of Working Group I to the Fifth Assessment Report of the Intergovernmental Panel on Climate Change, edited by: Stocker, T. F., Qin, D., Plattner, G.-K., Tignor, M., Allen, S. K., Boschung, J., Nauels, A., Xia, Y., Bex, V., and Midgley, P. M.: Cambridge Univ. Press, Cambridge, UK, and New York, https://doi.org/10.1017/CBO9781107415324, 1535 pp., 2013.

Jin, H. and Nasiri, S. L.: Evaluation of AIRS cloud-thermodynamicphase determination with CALIPSO, J. Appl. Meteor. Climatol., 53, 1012-1027, 2014.

Kahn, B. H., Nasiri, S. L, Schreier, M. M., and Baum, B. A.: Impacts of subpixel cloud heterogeneity on infrared thermodynamic phase assessment, J. Geophys. Res., 116, D20201, https://doi.org/10.1029/2011JD015774, 2011.

Kahn, B. H., Irion, F. W., Dang, V. T., Manning, E. M., Nasiri, S. L., Naud, C. M., Blaisdell, J. M., Schreier, M. M., Yue, Q., Bowman, K. W., Fetzer, E. J., Hulley, G. C., Liou, K. N., Lubin, D., Ou, S. C., Susskind, J., Takano, Y., Tian, B., and Worden, J. R.: The Atmospheric Infrared Sounder version 6 cloud products, Atmos. Chem. Phys., 14, 399-426, https://doi.org/10.5194/acp-14-3992014, 2014.

Kalmus, P., Wong, S., and Teixeira, J.: The Pacific subtropical cloud transition: A MAGIC assessment of AIRS and ECMWF thermo- dynamic structure, IEEE Geosci. Remote Sens. Lett., 12, 15861590, https://doi.org/10.1109/LGRS.2015.2413771, 2015.

Karlsson, J., Svensson, G., Cardoso, S., Teixeira, J., and Paradise, S.: Subtropical cloud-regime transitions: boundary layer depth and cloud-top height evolution in models and observations, J. Appl. Meteor. Climatol., 49, 1845-1858, 2010.

Kawai, H. and Teixeira, J.: Probability density functions of liquid water path and cloud amount of marine boundary layer clouds: Geographical and seasonal variations and controlling meteorological factors, J. Clim., 23, 2079-2092, 2010.

Kawai, H. and Teixeira, J.: Probability density functions of liquid water path and total water content of marine boundary layer clouds: Implications for cloud parameterization, J. Clim., 25, 2162-2177, 2012.

Klein, S. A. and Hartmann, D. L.: The seasonal cycle of low stratiform clouds, J. Clim., 6, 1587-1606, 1993.

Kubar, T. L., Waliser, D. E., Li, J.-L., and Jiang, X.: On the annual cycle, variability, and correlations of oceanic low-topped clouds with large-scale circulation using Aqua MODIS and ERA-Interim, J. Clim., 25, 6152-6174, 2012.

Kubar, T. L., Stephens, G. L., Lebsock, M., Larson, V. E., and Bogenschutz, P. A.: Regional assessments of low clouds against large-scale stability in CAM5 and CAM-CLUBB using MODIS and ERA-Interim reanalysis data, J. Clim., 28, 1685-1706, 2015.

Lau, K. M. and Kim, K.-M.: Robust Hadley circulation changes and increasing global dryness due to $\mathrm{CO}_{2}$ warming from CMIP5 model projections, P. Natl. Acad. Sci. USA, 112, 3630-3635, 2015.

L'Ecuyer, T. S. and Stephens, G. L.: An estimation-based precipitation retrieval algorithm for attenuating radars, J. Appl. Meteor., 41, 272-285, 2002.

Liang, L., Di Girolamo, L., and Sun, W: Bias in MODIS cloud drop effective radius for oceanic water clouds as deduced from optical thickness variability across scattering angles, J. Geophys. Res.-Atmos., 120, 7661-7681, https://doi.org/10.1002/2015JD023256, 2015.

Maddy, E. S. and Barnet, C. D.: Vertical resolution estimates in Version 5 of AIRS operational retrievals, IEEE Trans. Geosci. Remote Sens., 46, 2375-2384, 2008.

Martins, J. P. A., Teixeira, J., Soares, P. M. M., Miranda, P. M. A., Kahn, B. H., Dang, V. T., Irion, F. W., Fetzer, E. J., and Fishbein, E.: Infrared sounding of the trade-wind boundary layer: AIRS and the RICO experiment, Geophys. Res. Lett., 37, L24806, https://doi.org/10.1029/2010GL045902, 2010.

Medeiros, B. P. and Stevens, B.: Revealing differences in GCM representations of low clouds, Clim. Dynam., 36, 385-399, 2011.

Medeiros, B. P. and Nuijens, L.: Clouds at Barbados are representative of clouds across the trade wind regions in observations and climate models, P. Natl. Acad. Sci. USA, 113, E3062-70, https://doi.org/10.1073/pnas.1521494113, 2016.

Muhlbauer, A., McCoy, I. L., and Wood, R.: Climatology of stratocumulus cloud morphologies: microphysical properties and radiative effects, Atmos. Chem. Phys., 14, 6695-6716, https://doi.org/10.5194/acp-14-6695-2014, 2014.

Myers, T. A. and Norris, J. R.: On the relationship between subtropical clouds and meteorology in observations and CMIP3 and CMIP5 models, J. Clim., 28, 2945-2967, 2015.

Nam, C., Bony, S., Dufresne, J.-L., and Chepfer, H.: The "too few, too bright" tropical low-cloud problem 
in CMIP5 models, Geophys. Res. Lett., 39, L21801, https://doi.org/10.1029/2012GL053421, 2012.

Nuijens, L. and Stevens, B.: The influence of wind speed on shallow marine cumulus convection, J. Atmos. Sci., 69, 168-184, 2012.

Nuijens, L., Stevens, B., and Siebesma, A. P.: The environment of precipitating shallow cumulus convection, J. Atmos. Sci., 66, 1962-1979, 2009.

Oreopoulos, L. and Cahalan, R. F.: Cloud inhomogeneity from MODIS, J. Clim., 18, 5110-5124, 2005.

Platnick, S., Ackerman, S. A., King, M. D., Meyer, K., Menzel, W. P., Holz, R. E., Baum, B. A., and Yang, P.: MODIS atmosphere L2 cloud product (06_L2), NASA MODIS Adaptive Processing System, Goddard Space Flight Center https://doi.org/10.5067/MODIS/MYD06_L2.006, 2015.

Platnick, S., Meyer, K. G., King, M. D., and Coauthors: The MODIS cloud optical and microphysical products: Collection 6 updates and examples from Terra and Aqua, IEEE Trans. Geosci. Remote Sens., 55, 502-525, 2017.

Rapp, A. D., Lebsock, M., and L'Ecuyer, T.: Low cloud precipitation climatology in the southeastern Pacific marine stratocumulus region using CloudSat, Environ. Res. Lett., 8, 1-11, https://doi.org/10.1088/1748-9326/8/1/014027, 2013.

Rieck, M., Nuijens, L., and Stevens, B.: Marine boundary layer cloud feedbacks in a constant relative humidity atmosphere, J. Atmos. Sci., 69, 2538-2550, 2012.

Rienecker, M. M., Suarez, M. J., Gelaro, R., and Coauthors: MERRA: NASA's Modern-Era Retrospective Analysis for Research and Applications, J. Clim., 24, 3624-3648, https://doi.org/10.1175/JCLI-D-11-00015.1, 2011.

Rossow, W. B. and Schiffer, R. A.: Advances in Understanding Clouds from ISCCP, B. Am. Meteorol. Soc., 72, 2-20, 1999.

Schreier, M. M., Kahn, B. H., Eldering, A., Elliott, D. A., Fishbein, E., Irion, F. W., and Pagano, T. S.: Radiance comparisons of MODIS and AIRS using spatial response information, J. Atmos. Ocean. Tech., 27, 1331-1342, https://doi.org/10.1175/2010JTECHA1424.1, 2010.

Sherwood, S. C., Ingram, W., Tsushima, Y., Satoh, M., Roberts, M., Vidale, P. L., and O'Gorman, P. A.: Relative humidity changes in a warmer climate, J. Geophys. Res., 115, D09104, https://doi.org/10.1029/2009JD012585, 2010.

Stephens, G. L.: Cloud feedbacks in the climate system: A critical review, J. Clim., 18, 237-273, 2005.

Stephens, G. L., Vane, D. G., Boain, R. J. et al.: The CloudSat mission and the A-train, Bull. Amer. Meteor. Soc., 83, 1771-1790, 2002.

Suselj, K., Teixeira, J., and Chung, D.: A unified model for moist convective boundary layers based on a stochastic eddydiffusivity/mass-flux parameterization, J. Atmos. Sci., 70, 19291953, 2013.

Suzuki, K., Nakajima, T., Nakajima, T. Y., and Khain, A. P.: A study of microphysical mechanisms for correlation patterns between droplet radius and optical thickness of warm clouds with a spectral bin microphysics cloud model, J. Atmos. Sci., 67, 11261141, 2010a.

Suzuki, K., Nakajima, T., Nakajima, T. Y., and Stephens, G. L.: Effect of the droplet activation process on microphysical properties of warm clouds, Environ. Res. Lett., 5, 1-6, https://doi.org/10.1088/1748-9326/5/2/024012, 2010 b.
Teixeira, J., Cardoso, S., Bonazzola, M., and Coauthors: Tropical and subtropical cloud transitions in weather and climate prediction models: The GCSS/WGNE Pacific cross-section intercomparison (GPCI), J. Clim., 24, 5223-5256, 2011.

von Engeln, A., Teixeira, J., and Beyerle, G.: Impact of thin water vapor layers on CHAMP radio occultation measurements, Radio Sci., 42, RS2010, https://doi.org/10.1029/2005RS003379, 2007.

Weber, T., Quaas, J., and Räisänen, P.: Evaluation of the statistical cloud scheme in the ECHAM5 model using satellite data, Q. J. R. Meteor. Soc., 137, 2079-2091, https://doi.org/10.1002/qj.887, 2011.

Wood, R.: Stratocumulus Clouds, Month. Weather Rev., 140, 2373 2423, https://doi.org/10.1175/MWR-D-11-00121.1, 2012.

Wood, R. and Field, P. R.: The Distribution of Cloud Horizontal Sizes, J. Clim., 24, 4800-4816, https://doi.org/10.1175/2011JCLI4056.1, 2011.

Wood, R. and Bretherton, C. S.: Boundary layer depth, entrainment and decoupling in the cloud-capped subtropical and tropical marine boundary layer, J. Clim., 17, 3576-3588, 2004.

Wood, R. and Hartmann, D. L.: Spatial variability of liquid water path in marine boundary layer clouds: The importance of mesoscale cellular convection, J. Clim., 19, 1748-1764, 2006.

Yue, Q., Kahn, B. H., Fetzer, E. J., and Teixeira, J.: Relationship between oceanic boundary layer clouds and lower tropospheric stability observed by AIRS, CloudSat, and CALIOP, J. Geophys Res., 116, D18212, https://doi.org/10.1029/2011JD016136, 2011.

Yue, Q., Kahn, B. H., Xiao, H., Schreier, M. M., Fetzer, E. J., Teixeira, J., and Suselj, K.: Transitions of cloud-topped marine boundary layers characterized by AIRS, MODIS, and a large eddy simulation model, J. Geophys. Res.-Atmos., 118, 85988611, https://doi.org/10.1002/jgrd.50676, 2013.

Yue, Q., Kahn, B. H., Fetzer, E. J., Wong, S., Frey, R., and Meyer, K. G.: On the response of MODIS cloud coverage to global mean surface air temperature, J. Geophys. Res.-Atmos., 122, 966-979, https://doi.org/10.1002/2016JD025174, 2017.

Zelinka, M. D., Klein, S. A., and Hartmann, D. L.: Computing and partitioning cloud feedbacks using cloud property histograms, Part II: Attribution to changes in cloud amount, altitude, and optical depth, J. Clim., 25, 3736-3754, 2012.

Zhang, Z., Ackerman, A. S., Feingold, G., Platnick, S., Pincus, R., and Xue, H.: Effects of cloud horizontal inhomogeneity and drizzle on remote sensing of cloud droplet effective radius: Case studies based on large-eddy simulations, J. Geophys. Res., 117, D19208, https://doi.org/10.1029/2012JD017655, 2012.

Zhang, Z., Werner, F., Cho, H.-M., Wind, G., Platnick, S., Ackerman, A. S., Di Girolamo, L., Marshak, A., and Meyer, K.: A framework based on 2-D Taylor expansion for quantifying the impacts of subpixel reflectance variance and covariance on cloud optical thickness and effective radius retrievals based on the bispectral method, J. Geophys. Res.-Atmos., 121, 7007-7025, https://doi.org/10.1002/2016JD024837, 2016.

Zhao, G., Di Girolamo, L., Diner, D. J., Bruegge, C., J., Mueller, K. J., and Wu, D. L.: Regional changes in Earth's color and texture as observed from space over a 15-year period, IEEE Trans. Geosci. Remote Sens., 54, 4240-4249, 2016.

Zhu, P. and Zuidema, P.: On the use of PDF schemes to parameterize sub-grid clouds, Geophys. Res. Lett., 36, L05807, https://doi.org/10.1029/2008GL036817, 2009. 